\title{
REVISTA
}

\section{de MUSICOLOGÍA}

Vol. XXXVII No $12014 \quad$ Madrid

ISSN: 0210-1459

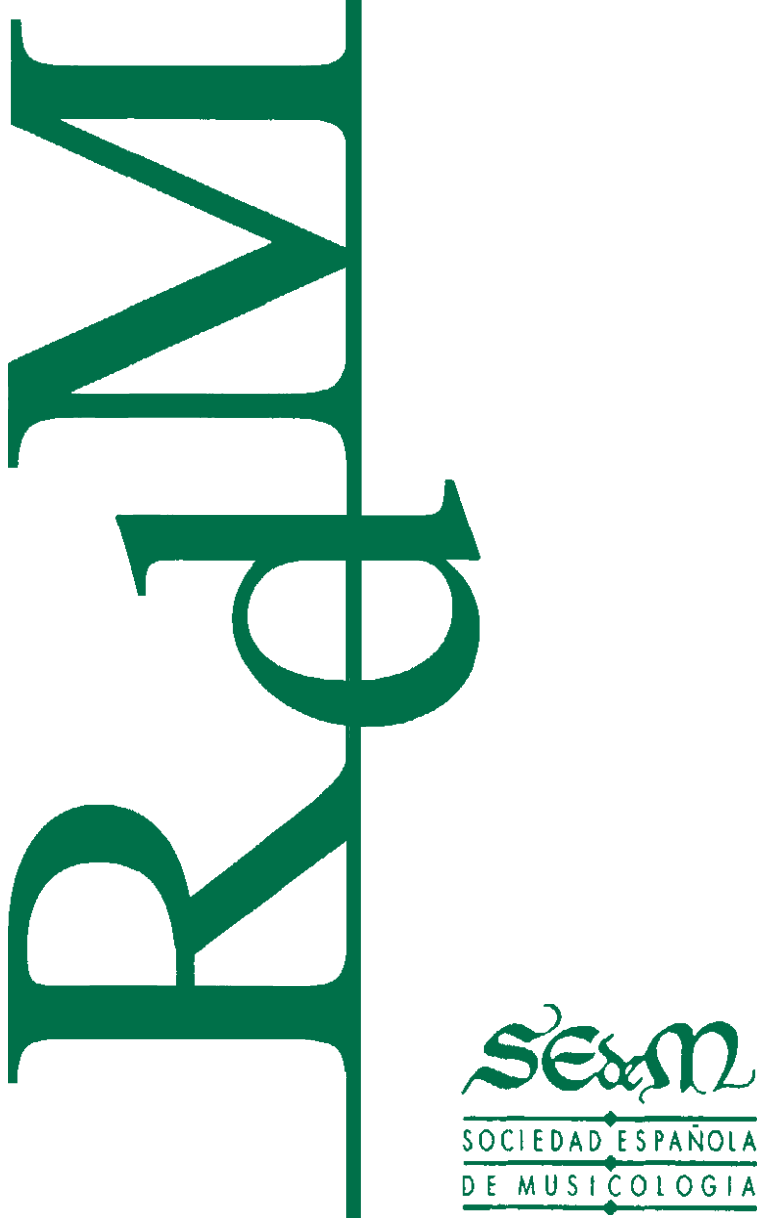




\section{REVISTA DE MUSICOLOGÍA \\ Vol. XXXVII, 1 (2014)}





\title{
SOCIEDAD ESPAÑOLA DE MUSICOLOGÍA
}

\author{
JUNTA DIRECTIVA \\ Presidente: Lothar Siemens Hernández (2007-) \\ Anteriores presidentes/a: †Samuel Rubio (1978-1984), Ismael Fernández de la Cuesta (1985-1994), \\ $†$ Dionisio Preciado (1995-1998), Rosario Álvarez Martínez (1999-2006) \\ Vicepresidente: José Antonio Gómez Rodríguez \\ Secretario: Francisco Rodilla León \\ Tesorero: Francisco Javier Roa Alonso \\ Vocales: Juan Pablo Fernández-Cortés, Javier Marín López, Inmaculada Matía Polo, \\ Pilar Ramos López, Elena Torres Clemente \\ Vocales natos: Rosario Álvarez Martínez, Ismael Fernández de la Cuesta \\ Administración: Ignacio Hurtado Puerta \\ Página web: www.sedem.es \\ Contacto: sedem@sedem.es
}

\section{REVISTA DE MUSICOLOGÍA}

Órgano científico de la Sociedad Española de Musicología

Fundada por Samuel Rubio en 1978

Periodicidad semestral

Revista evaluada por pares (peer review journal)

C/ Torres Miranda, 18, bajo

28045 Madrid (España)

Tel. y Fax: +34 915231712

Correo electrónico: revista@idecnet.com

Página web: www.sedem.es

\begin{abstract}
Indexada y resumida en bases de datos de relevancia nacional e internacional como CARHUS+ 2010 (AGAUR), CIRC (Clasificación Integrada de Revistas CientíficasEC3), Dialnet (Universidad de La Rioja), DICE (CSIC-ANECA), Dulcinea (Derechos de Copyright de Revistas Científicas Españolas), ERIH (European Reference Index for the Humanities), IN-RECH (Índice de Impacto Revistas Españolas de Ciencias Humanas), International Index to Music Periodicals y Music Index (EBSCO), ISOC (CSIC), Latindex (UNAM), MIAR (Matriz de Información para la Evaluación de Revistas), Periodical Index Online (Proquest), Regesta Imperii (Akademie der Wissenschaften und der Literatur), RESH (Revistas Españolas de Ciencias Sociales y Humanidades), RILM (Répertoire International de la Littérature Musicale). Accesible a texto completo en JSTOR.
\end{abstract}

Ni la Sociedad Española de Musicología ni el equipo editorial se responsabilizan de las opiniones emitidas por los colaboradores en las diferentes secciones de la Revista de Musicología, puesto que son exclusivamente de su competencia.

C Sociedad Española de Musicología

I.S.S.N.: 0210-1459

Depósito Legal: M-38068-1978

Diseño de la cubierta: Mercè Franco Roca

Maqueta e imprime: Imprenta Taravilla, S.L. I Mesón de Paños, 6 | 28013 Madrid (España) 


\title{
REVISTA DE MUSICOLOGÍA
}

\author{
DIRECTOR \\ Javier Marín López, Universidad de Jaén \\ Comité Científico
}

Celsa Alonso González, Universidad de Oviedo

Germán Gan Quesada, Universidad Autónoma de Barcelona

María Gembero-Ustárroz, Institución Milá y Fontanals (CSIC), Barcelona

Tess Knighton, ICREA-Institución Milá y Fontanals (CSIC), Barcelona / Clare College Cambridge

Yvan Nommick, Université Paul-Valéry Montpellier III

Luis Robledo Estaire, Real Conservatorio Superior de Música de Madrid

Pilar Ramos López, Universidad de La Rioja

Elena Torres Clemente, Universidad Complutense de Madrid

Leonardo J. Waisman, Universidad Nacional de Córdoba (Argentina)

COORDINADOR DE RESEÑAS BIBLIOGRÁFICAS

José Máximo Leza, Universidad de Salamanca

COORDINADOR DE RESEÑAS DISCOGRÁFICAS

Pablo-L. Rodríguez, Universidad de La Rioja

EQUIPO TÉCNICO

Secretaría y correspondencia: Ana Llorens Martín, St John's College Cambridge

Proceso técnico e imprenta: Francisco Javier Roa Alonso, IES Tirso de Molina, Madrid

Revisión de textos en castellano: Cristina Aguilar Hernández, Universidad Complutense de Madrid Revisión de textos en inglés: Drew Edward Davies, Northwestern University (Estados Unidos)

\section{Consejo AsEsor}

Rosario Álvarez Martínez, Universidad de La Laguna

Jon Bagüés, Eresbil. Archivo de Compositores Vascos

Cristina Bordas, Universidad Complutense de Madrid

Enrique Cámara de Landa, Universidad de Valladolid Juan José Carreras, Universidad de Zaragoza

Andrés Cea Galán, Conservatorio Superior de Música de Sevilla

Walter Aaron Clark, University of California, Riverside

Hermann Danuser, Humboldt-Universität, Berlín

Gerhard Doderer, Universidade Nova de Lisboa

Dinko Fabris, Universitá della Basilicata, Pontenza

Ismael Fernández de la Cuesta, Real Academia de Bellas Artes de San Fernando

Antonio Gallego, Real Academia de Bellas Artes de San Fernando

José Antonio Gómez Rodríguez, Universidad de Oviedo

Josep Maria Gregori, Universidad Autónoma de Barcelona John Griffiths, University of Melbourne

Louis Jambou, Université Paris Sorbonne IV

Rainer Kleinertz, Universität des Saarlandes, Saarbrücken Luis Merino, Universidad de Chile

Ricardo Miranda, Universidad Veracruzana de Xalapa (México)

Begoña Lolo, Universidad Autónoma de Madrid

Antonio Martín Moreno, Universidad de Granada

Ángel Medina Álvarez, Universidad de Oviedo

Don Michael Randel, Andrew W. Mellon Foundation, Nueva York

Emilio Ros-Fábregas, Institución Milá y Fontanals (CSIC), Barcelona

Lothar Siemens Hernández, El Museo Canario, Las Palmas

Javier Suárez-Pajares, Universidad Complutense de Madrid Cristina Urchueguía, Universität Bern

Carlos Villanueva, Universidad de Santiago de Compostela

María Antonia Virgili, Universidad de Valladolid

Álvaro Zaldívar Gracia, Conservatorio Superior de Música de Murcia 



\section{REVISTA DE MUSICOLOGÍA}

Volumen XXXVII, $\mathrm{n}^{\circ} 1$

Enero-Junio 2014

ÍNDICE

Javier MARín LóPEz: Editorial: Musicología(s) sin fronteras

\section{ARTí́CULOS}

Juan Carlos Asensio Palacios: More hispano / more toletano. La elección del cantus firmus no romano en las tradiciones polifónicas locales hispanas hasta $c a .1600$

Juan Ruiz Jiménez: Música tras la muerte: dotaciones privadas y espacios rituales en la Catedral de Sevilla (siglos XIII-XVI)

Maricarmen Gómez Muntané: En memoria de Alixandre de Juan de Anchieta en su contexto

Manuel del SoL: Lamentaciones de Cristóbal de Morales: historia y autenticidad

Margarita Restrepo: Propagando la Contrarreforma: los madrigales de Francisco Guerrero en Canciones y villanescas espirituales (Venecia, 1589)

Esperanza Rodríguez-GARCía: Sebastián Raval (†1604)and «Spanish Arrogance»: How the Reputation of a Sixteenth-Century Composer was Destroyed .. 


\section{RESEÑAS BIBLIOGRÁFICAS}

Arturo Tello Ruiz-Pérez: Cruz y glorias del medievalista.

Gómez, Maricarmen (ed.). Historia de la Música en España e Hispanoamérica. Vol. I: De los orígenes hasta c. 1470

Alfonso de VICEnTE: Geografía e historia del ¿Renacimiento?

Gómez, Maricarmen (ed.). Historia de la Música en España e Hispanoamérica. Vol. II: De los Reyes Católicos a Felipe II

Egberto Bermúdez: Der Fall Zipoli.

Illari, Bernardo. Domenico Zipoli. Para una genealogía de la música clásica latinoamericana

Ricardo Miranda: In Stevenensonis festivitatem.

O'Connor, Michael y Clark, Walter Aaron (eds.). Treasures of the Golden Age. Essays in honor of Robert M. Stevenson

Daniele V. FILIPPI: Victoria, España y los Habsburgo. Variaciones sobre el método. Vicente, Alfonso de y Tomás, Pilar (eds.). Tomás Luis de Victoria y la cultura musical en la España de Felipe III .

Emilio Ros-Fábregas: Nuevas perspectivas sobre Tomás Luis de Victoria. Suárez-Pajares, Javier y Sol, Manuel del (eds.). Estudios. Tomás Luis de Victoria. Studies

Cristina Urchueguía: Abordaje a la música teatral del XVI con algunos cabos sueltos.

Klauk, Stephanie. Musik im spanischen Theater des 16. Jahrhunderts.....

Juan Carlos Asensio Palacios: Medievalismo, Ilustración e Identidad. Boynton, Susan. Silent Music: Medieval Song and the Construction of History in Eighteenth Century Spain

Gemma Pérez Zalduondo: La crítica musical a examen.

Cascudo, Teresa y Palacios, María (eds.). Los señores de la crítica. Periodismo musical e ideología del modernismo en Madrid (1900-1950)..

\section{RESEÑAS DISCOGRÁFICAS}

Pablo-L. RodríGUEz: El sonido moderno de la música sacra española del siglo XVII

José María Domínguez Rodríguez: «El estilo más gustoso» desde la atalaya andaluza: en torno a la recuperación e interpretación de la música del siglo XVIII en España

Fernando Delgado García: De cuartetos de cuerda y patrimonio 


\section{TESIS DOCTORALES}

Philippe Picone: Musiques et culte de Saint Jacques-le-Majeur dans l'Europe baroque (Espagne, France, Italie), 1563-1746

Alberto Hernández Mateos: El pensamiento musical de Antonio Eximeno

Virginia SáNchez López: Jaén y la música en el siglo XIX. La vida musical en una provincia española a través de la prensa

Isabel María Ayala Herrera: Música y municipio: marco normativo y administración de las bandas civiles en España (1931-1986). Estudio en la provincia de Jaén

Pedro Ordóñez Eslava: La creación musical de Mauricio Sotelo y José María Sánchez-Verdú: convergencia interdisciplinar a comienzos del siglo XXI ...

\section{NOTICIAS}

Yael Bitrán Goren y Omar Morales Abril: Músicas coloniales en Úbeda y Baeza

Josep Martínez Reynoso: Investigar sin complejos: nuevas perspectivas de estudio sobre la música en España en el siglo XVIII ....

Antonio Álvarez CAÑIBAnO: Músicas para tiempos convulsos ....................... 353

Mario Muñoz CarRasco: Manuel de Falla como punto de partida ................ 355

Instrucciones para los colaboradores de la Revista de Musicología .......... 359

Publicaciones de la Sociedad Española de Musicología ........................... 367 



\title{
LAMENTACIONES DE CRISTÓBAL DE MORALES. HISTORIA Y AUTENTICIDAD*
}

\author{
Manuel del Sol \\ Universidad Complutense de Madrid
}

Resumen: Las lamentaciones de Cristóbal de Morales presentan una compleja red de relaciones contradictorias debido a la variedad de versiones conservadas. De hecho, la música y los textos originales de algunas de estas lecciones de Tinieblas han sido distorsionadas de tal manera en diversas fuentes manuscritas e impresas que casi no se reconoce la intencionalidad de su autor, de ahí que los problemas relacionados con la autenticidad y autoría de estas composiciones hayan dominado las investigaciones de un importante grupo de estudiosos en las últimas cinco décadas. A través de la colación crítica de todas las lamentaciones atribuidas a Morales ha sido posible la actualización de su catálogo y la diferenciación de las lecciones compuestas por el propio compositor y las versiones alteradas que se produjeron tras su muerte. Además, otras lecciones de dudosa autoría no han permitido desentrañar, en el proceso de su catalogación, la trama enigmática de estas obras en sus contextos litúrgicos pre- y postridentino. Un repertorio que, desde la práctica musical de la Capilla Papal en Roma, disfrutó de

* La investigación para la preparación de este artículo fue posible gracias al apoyo económico del Departamento de Música de Royal Holloway y Bedford New College, University of London (2005-2006); del Proyecto de I+D «El canto llano en la época de la polifonía» (2011-2014) del Ministerio de Economía y Competitividad del Gobierno de España (Universidad Complutense de Madrid, HAR2010-17398); del Proyecto de I+D «Música y cultura en el reino de Castilla (siglos XVI-XIX)» (2011-2014) del Ministerio de Economía y Competitividad del Gobierno de España (Universidad de Valladolid, HAR2011-30272-C02-01); y del Programa «Jóvenes Excelentes» de la Fundación Gutiérrez Manrique de Caja de Burgos-Fundación - CaixaBank (2009-2014) que financia mi Tesis Doctoral con Mención Europea, La tradición monódica hispana en las lamentaciones polifónicas del Renacimiento en España, bajo la tutela de Tess Knighton (University of Cambridge / ICREA Research Professor, Institució Milà i Fontanals) y Álvaro Torrente (Universidad Complutense de Madrid). 
una fama internacional preeminente en la segunda mitad del siglo XVI. Las lamentaciones de Morales fueron, junto con sus misas y magníficats, las obras más conocidas del compositor.

Palabras clave: Cristóbal de Morales, Costanzo Festa, Opera omnia, lamentaciones de Jeremías, Capilla Papal, Concilio de Trento, Higinio Anglés, Samuel Rubio.

\section{THE LAMENTATION SETTINGS OF CRISTÓBAL DE MORALES: HISTORY AND AUTHENTICITY}

Abstract: Because of the variety of surviving versions, the lamentation settings of Cristóbal de Morales present us with a complex network of contradictory relationships. In fact, some sources of these lessons for the Office of Tenebrae, both manuscript and print, transmit the original music and liturgical texts in such distorted form that the composer's intentions have been obscured almost beyond recognition. Thus, questions related to the authenticity and authorship of these compositions have dominated studies by an important group of scholars over the last five decades. Nonetheless, the critical comparison of all of the lamentation settings attributed to Morales now enables the composer's worklist to be updated with a clear differentiation between the versions actually composed by Morales and those that were altered after his death. Furthermore, other lessons of doubtful attribution have impeded tracing the enigmatic path of these works in their pre- and post-Tridentine liturgical contexts. The lamentations, whose performance by the Papal Chapel in Rome assured them a preeminent position of international renown in the second half of the 16th century, were the most widely known works of the composer, together with his masses and the magnificats.

Keywords: : Cristóbal de Morales, Costanzo Festa, Opera omnia, Lamentations of Jeremiah, Papal Chapel, Council of Trent, Higinio Anglés, Samuel Rubio.

El interés que la musicología decimonónica centroeuropea demostró por difundir las obras completas de los grandes maestros de la historia de la música occidental produjo en la Alemania de finales del siglo XIX —a través del trabajo de Felipe Pedrell— la publicación de la Opera omnia de Tomás Luis de Victoria (1902-1913)1, uno de los más importantes proyectos de la musicología española moderna, al que le siguió muy tardíamente, casi medio siglo después, la colección «Monumentos de la Música Española» (MME) de la Escuela Española de Historia y Arqueología en Roma y del Instituto Español de Musicología (actual Departamento de Ciencias Históricas: Musicología, de la Institución Milá y Fontanals del CSIC)². En

\footnotetext{
${ }^{1}$ Thomae Ludovici Abulensis Victoria. Opera omnia. Felipe Pedrell (ed.). 8 vols. Leipzig, Breitkopf \& Härtel, 1902-1913.

${ }^{2}$ Cristóbal de Morales. Opera omnia. Higinio Anglés (ed.). 10 vols. Roma, CSIC, 1952-1971. Sobre la reflexión historiográfica de las obras completas de Morales, véase URCHUEGUía, Cristina.
} 
relación a su contenido, el patrimonio musical de la Corte de los Reyes Católicos y de la dinastía de los Austrias fue el principal objetivo de Higinio Anglés —su primer director—, quien lideró desde 1941 hasta 1969 un ambicioso plan editorial centrado en el estudio y transcripción de los cancioneros musicales de Palacio, Medinaceli y la Biblioteca Colombina; varios libros de música de vihuela y órgano; la obra de los tratadistas y teóricos musicales más destacados del Siglo de Oro; y las obras completas de Cristóbal de Morales, Francisco Guerrero, Antonio de Cabezón, y una nueva edición corregida y ampliada de las obras de Tomás Luis de Victoria ${ }^{3}$, entre algunos de los más destacados maestros de la música española del siglo XVI. Sin embargo, a pesar de que los setenta y nueve volúmenes de los «Monumentos de la Música Española» reúnen en la actualidad una amplia colección de música vocal e instrumental del siglo XV al XX, las obras completas de Morales permanecen aún incompletas (1952-1971 / 2010).

TABla 1. Volúmenes editados de la Opera omnia de Cristóbal de Morales, 1952-1971.

\begin{tabular}{|c|c|l|c|}
\hline Opera omnia & Año & \multicolumn{1}{|c|}{ Título } & Vol. MME \\
\hline OpOm1 & 1952 & Missarum liber primus (Roma, 1544) & 11 \\
\hline OpOm2 & 1953 & Motetes I-XXV & 13 \\
\hline OpOm3 & 1954 & Missarum liber secundus (Roma, 1544) & 15 \\
\hline OpOm4 & 1956 & XVI Magnificat (Venecia, 1545) & 17 \\
\hline OpOm5 & 1959 & Motetes XXVI-L & 20 \\
\hline OpOm6 & 1962 & Missarum liber secundus (Roma, 1544) 2a Parte & 21 \\
\hline OpOm7 & 1964 & Misas Polifónicas XVII-XXI & 24 \\
\hline OpOm8 & 1971 & Motetes LI-LXXXV & 34 \\
\hline OpOm9 & - & Sin publicar & - \\
\hline OpOm10 & - & Sin publicar & - \\
\hline
\end{tabular}

\section{Lamentaciones de Cristóbal de Morales en el marco histórico de su Opera omnia}

La edición de la Opera omnia de Morales estaba bastante avanzada en la década de 1960, ya que se habían publicado siete de los diez volúme-

«Editing Cristóbal de Morales's Masses Today». Cristóbal de Morales: Sources, Influences, Reception. Owen Rees y Bernadette Nelson (eds.). Woodbridge, The Boydell Press, 2007, pp. 235-238.

${ }^{3}$ Tomás Luis de Victoria. Nueva edición corregida y aumentada. Higinio Anglés (ed.). 4 vols. Roma, CSIC, 1965-1968. 
nes proyectados por Anglés — director y editor principal— (Tabla 1). No obstante, su fallecimiento el 8 de diciembre de 1969 paralizó de forma imprevista el proyecto. Después fueron José María Llorens y Miguel Querol quienes retomaron la edición de Morales con la publicación del volumen octavo, interrumpiéndose la colección en 1971.

De los textos introductorios a los cinco primeros números se conocen algunos de los detalles más importantes relacionados con este proyecto; precisamente, en el quinto tomo quedó justificado tanto el plan de trabajo como la programación editorial prevista. Por un lado, Anglés explicó algunas de las causas que retrasaron la publicación de volúmenes anteriores y, por otro, propuso un plan correctivo por el que se pretendía poner al día la colección y establecer una agenda para finalizar los próximos libros. En relación a los volúmenes pendientes quedaron determinados los siguientes contenidos:

Tomo VI, preparado para 1960: contendrá las cuatro misas que nos restan por publicar de la edición de Roma, 1544, es decir, Missa Tu es vas electionis, Missa Gaude Barbara y Missa L' Homme Armé, todas ellas a cuatro voces, y Missa Quem dicunt homines, a cinco voces.

Tomo VII: cinco misas, las cuatro primeras a cuatro voces, la última a cinco: Missa Caça, Missa Super ut re mi fa sol la, Missa Super fa ut re ut fa sol la, Missa Desidle al cavallero y Missa Tristezas me matan. Por lo visto estas cinco misas no llegaron a imprimirse, ya que las fuentes conocidas hasta aquí son siempre manuscritas.

Tomo VIII: será destinado a una tercera sección de motetes. Como indiqué en el primer tomo, muchas de las obras de Morales se nos han conservado sólo manuscritas, como acontece con muchos de sus motetes.

Tomo IX: contendrá el Officium Hebdomadae Sanctae (Venecia, Antonio Gardano, 1564), con tres lamentaciones a cuatro voces, para la «Feria Quinta»; otras tres a cuatro voces, para la «Feria Sexta»; dos a cinco voces y la "Oratio Jeremiae Profetae» a seis, «in Sabbato Sancto». Además, de estas lamentaciones impresas se conservan varias manuscritas, más o menos completas, que tenemos transcritas y publicaremos a continuación de las impresas. En este tomo incluiremos también el Officium defunctorum, que quedó manuscrito [...].

Tomo X: Será destinado a una cuarta serie de motetes y otras piezas de nuestro maestro, y al estudio crítico de su obra ${ }^{4}$.

De haberse ejecutado esta programación, el volumen noveno hubiese reunido el estudio y transcripción del Officium Hebdomadae Sanctae y del Officium defunctorum, mientras que el décimo hubiera contenido la cuarta y última serie de motetes y una colección miscelánea de piezas de diversos géneros. Sin embargo, esta tarea nunca se llevó a término. Hubo que

${ }^{4}$ Cristóbal de Morales: Opera omnia V..., pp. 7-8. 
esperar hasta el año 2010, casi cuatro décadas después de la publicación del volumen octavo, para que el CSIC retomase de nuevo el pulso de la Opera omnia de Morales con la edición del tomo noveno dedicado al Officium defunctorum ${ }^{5}$. Así se pretende, acorde con la nueva agenda diseñada por Llorens, completar las obras completas de Morales con la edición del «último volumen ya preparado con el contenido de Himni, Lamentationes et alia» ${ }^{6}$. Mientras se espera esta publicación, algunas cuestiones deben esclarecerse en relación al proyecto original de Anglés, especialmente en lo que se refiere a las lamentaciones de Jeremías.

La preparación de una colección integral de obras para los Oficios de Semana Santa en el «tomo noveno» aporta una información contradictoria. No hay duda de que el título, Officium Hebdomadae Sanctae, es erróneo, ya que Morales nunca publicó en vida ni ordenó para después de su muerte un proyecto editorial de estas características. Esta información corresponde, por el contrario, a una de las dos series impresas de nueve lamentaciones polifónicas - con idéntico título y contenido (Lamentationi di Morales, a quatro, a cinque et sei voci) - publicadas en Venecia en 1564: una salida de la imprenta de Antonio Gardano y otra del taller de Francesco Rampazetto ${ }^{7}$. En relación a estos dos libros, parece lógico pensar que la edición de Rampazetto era una fuente desconocida para Anglés, ya que no se encuentra ninguna referencia a este libro en el prólogo del quinto volumen. Sin embargo, en el supuesto de que la transcripción de estas composiciones se hubiera basado sólo en el impreso de Gardano, su edición no hubiera planteado dificultades significativas. Aún siendo incompletos los ejemplares que se conservan de las ediciones de Gardano, estas son fuentes complementarias. Por otro lado, no hay duda de que el Instituto Español de Musicología habría localizado algunos de los ejemplares que se conservan de la edición de Rampazetto. Además, según el testimonio del propio Anglés, se conoce que para la realización del «tomo noveno» se había ubicado un grupo de lamentaciones manuscritas — «más o menos completas, que tenemos transcritas y publicaremos a continuación de las

\footnotetext{
${ }^{5}$ Cristóbal de Morales Opera omnia IX: Officium, Missa et Motecta defunctorum. José María Llorens (ed.). Barcelona, CSIC, 2010.

${ }^{6}$ Ibid., p. xiv.

${ }^{7}$ Morales, Cristóbal de. Lamentationi di Morales, a quatro, a cinque et sei voci. Venecia, Antonio Gardano, 1564 [RISM M3607], conservado en D-Brd, completo (S, A, T, B a 5); I-Bc (falta B) e I-Ls (falta S); y Morales, Cristóbal de. Lamentationi di Morales, a quatro, a cinque et sei voci. Venecia, Francesco Rampazetto, 1564 [RISM M3608]; S-Uu, completo (S, A, T, B a 5). En relación al estudio de la casa editorial de la familia Gardano, véase LewIs, Mary. Antonio Gardano, Venetian Music Printer 1538-1659: A Descriptive Bibliography and Historical Study. Volume 1: 1538-1659. Nueva York y Londres, Garland, 1988; Volume 2: 1550-1559 (1997); y Volume 3: 1559-1659 (2006).
} 
impresas»- procedentes del archivo musical de la Cappella Sistina y la Cappella Giulia en Roma ${ }^{8}$. Otra cuestión distinta, aún sin resolver, se centra en esclarecer el conocimiento que estos estudiosos tenían acerca de las relaciones contradictorias que se detectan entre algunas lamentaciones manuscritas e impresas.

La complejidad litúrgica y musical que presentan algunas de las lamentaciones pudo hacer de estas composiciones uno de los principales obstáculos que contribuyó a la paralización casi definitiva de las obras completas de Morales en la década de 1970. De hecho, el volumen noveno, editado recientemente por Llorens, contiene únicamente el estudio y transcripción del Officium defunctorum, quedando aplazada la edición de las lamentaciones de Jeremías para el último número de la colección. Esta hipótesis se plantea de manera conjunta con otros factores que igualmente pudieron motivar la interrupción del proyecto después del fallecimiento de su editor principal. Por un lado, en la década de 1970 se había localizado un número muy reducido de lamentaciones compuestas o atribuidas a Morales, y su estudio debió plantear serios problemas al intentar desentrañar las relaciones contradictorias que se observan entre fuentes manuscritas e impresas. Por otro, desde la muerte de Anglés, Llorens centró sus investigaciones en las obras completas de Guerrero, mientras que Querol trabajó intensamente en la publicación de una parte importante del repertorio barroco español. Por tanto, ningún académico del Instituto Español de Musicología retomó en aquel momento la obra inacabada de Anglés en lo relativo a la edición de las obras completas de Morales.

En resumen, la falta de interés de los sucesores de Anglés en el Instituto Español de Musicología, unida a las dificultades que planteaba la edición del resto de las obras de Morales, que no habían sido previamente publicadas - especialmente sus lamentaciones- pudieron ser algunas de las razones que produjeron la suspensión de la Opera omnia de Morales. Asimismo, Samuel Rubio y Robert Stevenson, que en la década de 1970 eran dos de los máximos especialistas en Morales y Victoria, tampoco mostraron interés por transcribir las lamentaciones del

${ }^{8}$ Cristóbal de Morales: Opera omnia $V$..., p. 8. Queda pendiente conocer qué ocurrió con toda la documentación de Higinio Anglés relacionada con las lamentaciones de Morales. En futuras investigaciones se podría considerar la posibilidad de realizar un estudio en los fondos documentales de la Biblioteca de Cataluña, el Departamento de Ciencias Históricas: Musicología de la Institución Milá y Fontanals del CSIC y su entorno familiar, con la finalidad de conocer hasta qué punto llegó el antiguo Instituto Español de Musicología en relación al estudio y transcripción de las lamentaciones de Morales. 
compositor hispalense ${ }^{9}$. El primer musicólogo que centró su atención en este repertorio fue el norteamericano Glenn Watkins, quien en su Tesis Doctoral (1953) realizó la primera transcripción del ciclo completo de las lamentaciones según la edición de Rampazetto. En el capítulo dedicado a Morales, este musicólogo desarrolló un estudio analítico en el que comparaba los textos de las lecciones publicadas en ese impreso, con una selección de libros litúrgicos tridentinos y los versos fijados en otros ciclos polifónicos contemporáneos. No obstante, al cotejar críticamente la edición de Rampazetto con varias de las lamentaciones manuscritas de Morales, Watkins descubrió un importante número de incoherencias textuales y melódicas. Tras alertar sobre las dificultades que planteaba la autenticidad de las lamentaciones de Morales, no halló solución para ellas, afirmando que «muchas cuestiones deben permanecer sin respuesta en este momento» ${ }^{10}$. Por otro lado, Anglés, que no debió de conocer el

\footnotetext{
${ }^{9}$ Stevenson, Robert. La música en las catedrales españolas del Siglo de Oro. Madrid, Alianza Editorial, 1993, pp. 110-115. Excepto la transcripción del impreso de Rampazetto (Venecia, 1564) realizada por Glenn Watkins (en Three Books of Polyphonic Lamentations of Jeremiah, 1549-1564. 2 vols. Ph.D.diss. University of Rochester, 1953), desde la década de 1990 hasta 2009 un pequeño grupo de estudiosos formado por Robert Snow, Frank D'Accone, José Climent, Gillian Bunshaft, Johannes Ring, Michael Noone, Graeme Skinner, Martin Ham y Manuel del Sol han transcrito total o parcialmente alguna lección original de Morales. Véase SNow, Robert. A New-World Collection of Polyphony for Holy Week and the Salve Service: Guatemala City, Cathedral Archive, Music Ms. 4. Bonnie Blackburn (ed.). Chicago y Londres, University of Chicago Press, 1996, pp. 321-327; D'AcCONE, Frank. «Singolarità di alcuni aspetti della musica sacra fiorentina del cinquecento». Firenze e la Toscana dei Medici nell' Europa del '500. Florencia, Biblioteca di Storia Toscana Moderna, 1983, vol. II, n 26, pp. 533-534; Bunshaft, Gillian. Biblioteca Nazionale Centrale, Manuscript II.I.285 (Magliabecchi XIX. 56): A Study. Master Thesis. University of Illinois, 1989, pp. 126-155 y 189-201; Climent, José. Cançoner de Gandia. Valencia, Conselleria de Cultura, 1995, pp. 321-326; RING, Johannes. Studien zu den mehrstimmigen Lamentationen des 16. Jahrhunderts: Escribano, Morales und Raval. Tesis Doctoral. Universität Hamburg, 2000, pp. 214-222; SoL, Manuel del. Polyphonic Settings of the Lamentations of Jeremiah by Cristóbal de Morales. Tesis de Máster. Royal Holloway y Bedford New College, University of London, 2006, pp. 41-56 y 73-80; Noone, Michael y SKINNER, Graeme. «The Nuevo Rezado, Music Scribes and the Restoration of Morales's Toledo Lamentation». Cristóbal de Morales: Sources, Influences, Reception..., pp. 19-20; HAM, Martin. «Morales: The Canon». Cristóbal de Morales: Sources, Influences, Reception..., pp. 274-275 y 277; y SoL, Manuel del. Lamentaciones de Cristóbal de Morales. Historia y autenticidad. DEA. Universidad Complutense de Madrid, 2009, pp. 102-184. También se ha publicado una transcripción y estudio basado en las investigaciones ya publicadas en SNOw, R. A New-World Collection of Polyphony...; y Cristóbal de Morales: Sources, Influences, Reception... Véase Martínez, Santiago. Lamentaciones. Cristóbal de Morales (c. 1500-1553). Madrid, Autor-Editor Santiago Martínez Alvira, 2011.

${ }^{10}$ Watkins, G. Three Books of Polyphonic Lamentations..., p. 112: «Upon what source, then, did Fuenllana base these transcriptions for the vihuela? Are they spurious? Did Morales possibly begin or even compete a second cycle of Lamentations which are unknown or unavailable to present day musical scholars? These and many more questions must be left unanswered at the present moment».
} 
trabajo doctoral de Watkins, también alertó de esta complejidad a través de las investigaciones de Rubio:

El otro problema que he encontrado [Anglés] al preparar la edición de Morales es el caso de la autenticidad de las obras, puesto que algunas llegan impresas como anónimas a pesar de que ciertamente son de Morales, como se ve por manuscritos posteriores. Sobre todo, desorienta en este punto el caso de las lamentaciones impresas en 1564, y atribuidas todas a Morales ${ }^{11}$.

El hecho de que las ediciones venecianas de Gardano y Rampazetto fueran consideradas parte de sus obras originales plantearon múltiples dificultades en aquel momento. Sin embargo, el contexto enigmático de estos dos libros quedó finalmente resuelto por Rubio, que tiene el mérito de haber descubierto que no todas las lecciones publicadas en estos impresos fueron escritas por Morales.

\section{Ediciones impresas: «¿una farsa editorial?»}

Mientras las ediciones impresas de los Magnificat de Morales son un punto de partida fiable para el estudio crítico de estas composiciones, esta misma certeza no se reconoce en sus lamentaciones. Ninguna obra de este género apareció publicada durante su vida y no fue hasta el año de 1564 - más de una década después de su muerte - cuando dos ediciones atribuidas a este compositor fueron publicadas en Venecia ${ }^{12}$. Ambos impresos son muy parecidos: formato similar en libros de partes del mismo tamaño, mismo número de páginas y distintas filigranas en sus temas. No obstante, un análisis de los tipos móviles y de la caligrafía del texto demuestra que son tiradas diferentes, lo que podría sugerir que una edición fue posterior a la otra ${ }^{13}$, aunque tampoco se descarta que se pre-

${ }^{11}$ ANGLÉs, Higinio. «Problemas que presenta la nueva edición de las obras de Morales y Victoria». Renaissance-muziek 1400-1600: Donum natalicium René Bernard Lenaert. Jozef Robijns et alii (eds.). Lovaina, Katholieke Universiteit, 1969, p. 28. Véase también Rubio, Samuel. «Las dos ediciones de las lamentaciones de Morales, del año 1564, son una farsa editorial». Tesoro Sacro Musical, 52 (1969), pp. 25-28; у Ruвiо, Samuel. Cristóbal de Morales. Estudio crítico de su polifonía. El Escorial, Biblioteca La Ciudad de Dios, 1969, pp. 280-286.

${ }^{12}$ Véanse más arriba las referencias bibliográficas de la nota 7.

${ }^{13}$ En el análisis comparativo entre ambas ediciones se han encontrado diferencias en los siguientes aspectos editoriales: distinta notación del texto y de los tipos móviles musicales; alteraciones con diferente diseño; signos de prolongación (puntillo en forma de diamante en Gardano y redondo en Rampazetto); notación desigual en la paginación (arábiga en Gardano y romana en Rampazetto); y el número de sistemas por página (cinco sistemas en Gardano, mientras que Rampazetto incluyó seis). 
pararan en paralelo. La edición de Rampazetto aparenta ser la segunda, ya que su diseño y maquetación parece más elaborada que la estampada por Gardano; sin embargo, esta hipótesis permanece abierta a nuevas interpretaciones. También se da la circunstancia de que ninguna de las dos ediciones incluye una dedicatoria, pero ambas se adjudican la novedad de su impresión con la publicación en sus portadas de la siguiente nota: «novamente con ogni diligentia stampate, et date in luce» ${ }^{14}$.

La publicación de dos ediciones contemporáneas con las lamentaciones de Morales sugiere que el gran éxito de la primera colección llevó a que otro editor se embarcarse en la empresa de reimprimir una segunda tirada de manera inmediata. La simultaneidad de ambos libros, en el mismo año y ciudad, debe catalogarse como un hecho sin precedentes, ya que esta no fue una práctica común en este repertorio. La preferencia de la industria tipográfica por divulgar lamentaciones polifónicas en antologías parece haber perdido interés en favor de una mayor valoración de la individualidad del compositor a partir de la década de 1560. Sólo una edición monográfica pretridentina anterior a las de Morales y Giovanni Nasco tuvo una destacada repercusión en Europa: las lamentaciones de Elzéar Genet «Carpentras» (Tabla 2) ${ }^{15}$.

${ }^{14}$ Véase Lewis, M. Antonio Gardano, Venetian Music Printer 1538-1659..., vol. 3, pp. 228-230. No se conoce el número de ejemplares publicados.

${ }^{15}$ A finales del siglo XVI, el teórico italiano Pietro Pontio destacó que las lamentaciones de Morales, Nasco y Contino eran obras excepcionales en el tratamiento musical del texto. Véase Pontio, Pietro. Dialogo del R. M. Don Pietro Pontio Parmigiano ove si tratta della theorica, e prattica di musica. Parma, Viotto, 1595, p. 61: «Ne si debe in simili componimenti far inventione alcuna ò almeno poche; ma solo esprimer le parole, como si vede nelle lamentationi di Morales, Gioanni Nasco, Gioanni Contino». 
TABLA 2. Ediciones impresas de lamentaciones polifónicas pretridentinas, 1506-1564.

\begin{tabular}{|c|c|c|c|c|c|c|}
\hline Formato & Año & Compositor & No. & Editor & $\begin{array}{c}\text { Tono } \\
\text { Romano }\end{array}$ & $\begin{array}{c}\text { Tono } \\
\text { Hispano }\end{array}$ \\
\hline Antología & 1506 & $\begin{array}{c}\text { Johannes Tinctoris } \\
\text { Bernart Icart } \\
\text { Anónimo } \\
\text { Alexander Agricola } \\
\text { Marbrianus Orto } \\
\text { Johannes de Quadris }\end{array}$ & $\begin{array}{l}1 \\
3 \\
1 \\
6 \\
1 \\
9\end{array}$ & Ottaviano Petrucci & $\begin{array}{l}\mathrm{x} \\
\mathrm{x} \\
\mathrm{x} \\
\mathrm{x} \\
\mathrm{x}\end{array}$ & $\mathrm{x}$ \\
\hline Antología & 1506 & $\begin{array}{c}\text { Bartolomeo Trombocino } \\
\text { Gaspar van Weerbeke } \\
\text { Erasmus Lapicida }\end{array}$ & $\begin{array}{l}9 \\
6 \\
3\end{array}$ & Ottaviano Petrucci & $\begin{array}{l}x \\
x \\
x\end{array}$ & \\
\hline Monografía & 1532 & Elzéar Genet «Carpentras» & 9 & Jean de Channay & $\mathrm{x}$ & \\
\hline Antología & 1534 & $\begin{array}{c}\text { Robert de Fevin } \\
\text { Claudin de Sermisy }\end{array}$ & $\begin{array}{l}2 \\
3\end{array}$ & Pierre Attaingnant & $\begin{array}{l}x \\
x\end{array}$ & \\
\hline Monografía & 1538 & Stephan Mahu & 9 & Georg Rhaw & $x$ & \\
\hline Antología & 1538 & $\begin{array}{c}\text { Anónimo } \\
\text { Heinrich Isaac }\end{array}$ & $\begin{array}{l}1 \\
1\end{array}$ & Georg Rhaw & $\begin{array}{l}x \\
x\end{array}$ & \\
\hline Antología & 1549 & $\begin{array}{c}\text { Thomas Crecquillon } \\
\text { Antoine de Fevin } \\
\text { Johannes Gardano } \\
\text { Pierre de La Rue } \\
\text { Claudin de Sermisy }\end{array}$ & $\begin{array}{l}6 \\
3 \\
3 \\
3 \\
3\end{array}$ & Berg \& Neuber & $\begin{array}{l}x \\
x \\
x \\
x \\
x\end{array}$ & $\mathrm{x}$ \\
\hline Antología & 1557 & $\begin{array}{c}\text { Jacques Arcadelt } \\
\text { Elzéar Genet «Carpentras» } \\
\text { Costanzo Festa } \\
\text { Antoine de Fevin } \\
\text { Claudin de Sermisy }\end{array}$ & $\begin{array}{l}2 \\
9 \\
9 \\
2 \\
3\end{array}$ & Le Roy \& Ballard & $\begin{array}{l}\mathrm{x} \\
\mathrm{x} \\
\mathrm{x} \\
\mathrm{x} \\
\mathrm{x}\end{array}$ & \\
\hline Monografía & 1561 & Giovanni Contino & 9 & Girolamo Scotto & $x$ & \\
\hline Monografía & 1561 & Giovanni Nasco & 9 & Antonio Gardano & $x$ & \\
\hline Monografía & 1564 & Cristóbal de Morales & 9 & Antonio Gardano & $x$ & $\mathrm{x}$ \\
\hline Monografía & 1564 & Cristóbal de Morales & 9 & $\begin{array}{c}\text { Francesco } \\
\text { Rampazetto } \\
\end{array}$ & $x$ & $\mathrm{x}$ \\
\hline Monografía & 1564 & Giovanni Nasco & 9 & Antonio Gardano & $\mathrm{x}$ & \\
\hline
\end{tabular}


TABLA 3. Textos de las lamentaciones publicadas en las ediciones impresas de Antonio Gardano y Francesco Rampazetto, Venecia, 1564 (RISM M3607 / RISM M3608).

\begin{tabular}{|c|c|c|c|}
\hline Lectio & Incipit & Versos & Autor \\
\hline \multicolumn{4}{|c|}{ Jueves Santo } \\
\hline Lectio prima & $\begin{array}{l}\text { Incipit Lamentatio Hieremie Prophete. } \\
\text { Aleph. Quomodo sedet sola }\end{array}$ & I:1-2 & Festa \\
\hline Lectio secunda & Lamech. Cui comparabote & II:13,12;IV:3;I:16,11*^ & Festa \\
\hline Lectio tertia & Heth. Peccatum peccavit & I:8-9;I:11 & Festa \\
\hline \multicolumn{4}{|c|}{ Viernes Santo } \\
\hline Lectio prima & Phe. Audite obscero & I:18;IV:21;III:61-62,56,58*^ & Festa \\
\hline Lectio secunda & Sade. Quomodo obscuratum est & IV:1-2;III:19-21^ & Festa \\
\hline Lectio tertia & Coph. Vocavi amicos meos & I:19-21 & Morales \\
\hline \multicolumn{4}{|c|}{ Sábado Santo } \\
\hline Lectio prima & Zain. Candidiores nazarei & IV:7-9 & Morales \\
\hline Lectio secunda & Num. Vigilavit iugum iniquitatum & I:14-16 & Morales \\
\hline Lectio tertia & $\begin{array}{l}\text { Incipit Oratio Hieremie Prophete. } \\
\text { Recordare, Domini }\end{array}$ & $\mathrm{V}: 1-5$ & Morales \\
\hline
\end{tabular}

$\wedge$ Letra acróstica hebrea errónea

* Verso incompleto

De las nueve lamentaciones polifónicas que aparecen atribuidas a Morales en los impresos de 1564, no todas fueron compuestas por el compositor español. Las cinco primeras lamentaciones, es decir, las tres lecciones del Jueves Santo y las dos primeras del Viernes Santo, fueron obra de Costanzo Festa, mientras que el resto pertenecen a Morales (Tabla 3). Esta es la razón principal por la que las ediciones de Gardano y Rampazetto fueran valoradas, en palabras de Rubio, como una «farsa editorial» ${ }^{16}$. El conocimiento que Rubio tenía acerca de las lamentaciones manuscritas de Morales conservadas en I-Rvat CG XII.3 le indujo a plantear la posibilidad de que las ediciones de 1564 tuvieron como fuente original la antología de la Cappella Giulia: una valiosa colección de composiciones de Semana Santa que muestran signos evidentes de uso y contiene dos pasiones y una Misa de Difuntos de Carlos D'Argentilly, y una antología de lamentaciones compuestas por Elzéar Genet «Carpentras» (7), Juan Escribano (6), Costanzo Festa (8), Yvo Nau «Ivo Barry» (8) y Cristóbal de

${ }^{16}$ ANGLÉs, H. «Problemas que presenta la nueva edición de las obras de Morales...», p. 28: «Ha sido el Padre Samuel Rubio, monje del monasterio de El Escorial, quien al preparar su tesis doctoral Técnica, estilo y expresión en la polifonía de Cristóbal de Morales (Roma, Pontificio Instituto de Música Sacra, 1967) ha podido demostrar que las cinco primeras [lamentaciones] no son de Morales [...] Esto, que estudiando el estilo había visto que estas cinco [primeras] lamentaciones se apartaban mucho del estilo de Morales». Véanse las referencias bibliográficas de Samuel Rubio de la nota 11. 
Morales (3) ${ }^{17}$. Tal y como indica su dedicatoria, Federico Mario de Perugia finalizó este manuscrito el 31 de diciembre de 1543, cuando Morales y Festa servían como cantores en la capilla pontificia de Pablo III, por lo que ambos pudieron ser testigos del proceso de copia y uso posterior del manuscrito. Así pues, las obras de I-Rvat CG XII.3 deben considerarse el testimonio más importante sobre la autoría y la versión más fiable de las tres lamentaciones que Morales compuso en Roma para uso en la Capilla Papal -Coph. Vocavi amicos meos, Num. Vigilavit iugum iniquitatum y Phe. Expandit Syon-. Sin embargo, a pesar de las convincentes conclusiones de Rubio, I-Rvat CG XII.3 no es la única fuente manuscrita que puede relacionarse con los impresos de Gardano y Rampazetto.

Una importante colección de lamentaciones polifónicas copiadas en el manuscrito I-Fn Magl.56 de la Biblioteca Nacional de Florencia también puede conectarse con las versiones publicadas en 1564. El origen y procedencia de este códice están aún por determinar, pero existen suficientes indicios que relacionan su contenido con el entorno musical romano pretridentino ${ }^{18}$. Se trata de una antología de 45 lecciones de Tinieblas en la que están representadas algunas de las más grandes figuras de la música vocal religiosa de mediados del siglo XVI: Elzéar Genet «Carpentras» (3), Antoine Brumel (2), Costanzo Festa (3), Cristóbal de Morales (4), Jacob Arcadelt (2), Philippe Verdelot (1), Thomas Crecquillon (2) y anónimos $(28)^{19}$. Por un lado, en relación a las cuatro lamentaciones de Morales, se debe destacar el hecho de que además de conservar las tres lecciones del I-Rvat CG XII.3, el manuscrito I-Fn Magl.56 incluye una copia de la lección Zain. Candidiores nazarei, una lamentación que no se conserva en ningún ejemplar del Vaticano ${ }^{20}$. Por otro lado, en el caso de Festa, las tres

${ }^{17}$ Llorens, José María. Le opere musicali della Cappella Giulia: Manoscritti e edizioni fino al '700. Ciudad del Vaticano, Biblioteca Apostolica Vaticana, 1971, pp. 63-67.

${ }^{18}$ Bunshaft, G. Biblioteca Nazionale Centrale, Masnucript II.I.285..., pp. 55-91.

${ }^{19}$ En relación al estudio sistemático de fuentes musicales del Renacimiento, me gustaría expresar mi más sincero agradecimiento al profesor Herbert Kellman por su valiosa ayuda durante el tiempo que estuve investigando en los «Musicological Archives for Renaissance Manuscript Studies» de la University of Illinois en Urbana-Champaign (2009).

${ }^{20}$ Las conclusiones de Rubio también plantearon la posibilidad de que Gardano o Rampazetto hubieran realizado sus ediciones a partir de otros manuscritos distintos al códice I-Rvat CG XII.3. Véase Rubio, S. «Las dos ediciones de las lamentaciones de Morales...», p. 28: «No descartamos la posibilidad de que sean otras las fuentes utilizadas por los editores, teniendo en cuenta el detalle de que la Lamentación primera del Sábado Santo [Zain. Candidiores nazarei] no se conserva en ninguna de los manuscritos existentes en el Vaticano». Todavía son muchas y variadas las cuestiones que permanecen sin una respuesta definitiva, debido principalmente a la falta de documentación conservada que indetermina cuál o cuáles pudieron ser las fuentes manuscritas utilizadas por Gardano y Rampazetto. 
lecciones del manuscrito I-Fn Magl.56 concuerdan con tres de las cinco de este autor atribuidas a Morales en los impresos venecianos: Incipit Lamentatio. Aleph. Quomodo sedet sola, Phe. Audite obsecro universi y Sade. Quomodo obscuratum est.

El estudio de las lamentaciones manuscritas de Morales y Festa (IRvat CG XII.3 y I-Fn Mag1.56) y los impresos de 1564 demuestra que las variantes textuales y musicales son casi inexistentes en las lecciones del compositor italiano —al adecuarse mejor a la tradición romana-, mientras que las diferencias más notables se concentran en las lecciones de Morales. A pesar de que las lamentaciones Coph. Vocavi amicos meos y Num. Vigilavit iugum iniquitatum se copiaron casi idénticas en las ediciones impresas (con la salvedad de exiguas alteraciones melódicas y textuales ${ }^{21}$ ), la lamentación Phe. Expandit Syon sufrió una adaptación considerable. Esta obra no se publicó con su texto original, sino con los versos «Incipit Oratio Hieremiae Prophetae. Recordare, Domine, quid acciderit» (Tabla 4). Al comparar ambas versiones se reconoce que la extensión de la lección Phe. Expandit Syon no era lo suficientemente amplia como para realizar una adaptación integral de los cinco primeros versos de la Oración de Jeremías y, por consiguiente, en la reelaboración de los impresos de 1564 se descubre que la música del verso «Expandit Syon» se repitió en dos secciones distintas — «Recordare, Domine, quid acciderit» $\mathrm{y}$ «Cervicibus nostris»— $\mathrm{y}$ al material musical del verso «in circuitu eius hostes» se adaptó el texto «peccaverunt, et non sunt»"22. Además, el hecho de que el versículo «Justus est Dominus» fuese una sección suprimida en la adaptación impresa de la lamentación Phe. Expandit Syon confirma la reelaboración realizada sobre esta obra.

\footnotetext{
${ }^{21}$ En relación a las lamentaciones de Festa, la música del melisma de la letra hebrea Lamech de la lección Lamech. Cui comparabo te no se copió del manuscrito I-Rvat CG XII.3, sino que fue impresa una versión musical distinta que aún no ha sido identificada. Además, la lamentación Sade. Quomodo obscuratum est — que se copió en la fuente vaticana de la Cappella Giulia con sib en la armadura - en las ediciones de 1564 se publicó transportada sin alteraciones. Con respecto a Morales, la lamentación Coph. Vocavi amicos meos fue escrita con dos bemoles en la armadura y con $m i$ por tónica, mientras que en las ediciones impresas la armadura no tiene alteraciones y la música está un tono más alta que en la fuente manuscrita. Respecto a la lección Num. Vigilavit iugum iniquitatum, las voces aparecen intercambiadas: el cantus coincide tanto en el manuscrito como en las fuentes impresas, pero la distribución del resto de las voces es distinta; el tenor I, en I-Rvat CG XII.3, es el altus en los impresos; el tenor II es el altus; y el altus original se transcribió como la voz del quintus en los impresos. Además, el bassus II es el bajo generador en las ediciones impresas.

${ }^{22}$ Brauner, Mitchell P. The Parvus Manuscripts: A Study of Vatican Polyphony, ca. 1535 to 1580. Ph.D.diss. Brandeis University, 1982, pp. 256-274; SoL, M. Polyphonic Settings of the Lamentations..., pp. 57-68; y НАм, M. «Morales: The Canon...», pp. 274-275.
} 
Por último, en lo que respecta a la cuarta lamentación publicada en los impresos de 1564 -Zain. Candidiores nazarei- aún es muy poco lo que se conoce del contexto compositivo de esta obra. Sin embargo, debe destacarse que el manuscrito florentino es la única fuente alternativa de esta obra que permite asumir que se trata de una atribución correcta, sobre todo por tratarse de un manuscrito de supuesta procedencia romana.

TABLA 4. Copia original de la lamentación Phe. Expandit Syon de Morales en I-Rvat CG XXII.3 y adaptación en las ediciones impresas de Antonio Gardano y Francesco Rampazetto (1543-1564).

\begin{tabular}{|l|l|l|}
\hline \multicolumn{1}{|c|}{ I-Rvat CG XXII.3 (1543) } & \multicolumn{2}{|c|}{$\begin{array}{c}\text { Antonio Gardano (RISM M3607) y Francesco Rampazetto } \\
\text { (RISM M360), 1564 }\end{array}$} \\
\hline Original Phe. Expandit Syon & Adaptación & Ediciones Impresas \\
\hline Phe. & Phe. & Incipit Oratio Hieremiae Prophete \\
\hline Expandit Syon & Expandit Syon & Recordare, Domine, quid acciderit \\
\hline in circuitu eius hostes & Virgines mee et iuvenes & Pupilli facti \\
\hline menstruis inter eos & Sade. & Aquam nostram \\
\hline Sade. & Expandit Syon & Cervicibus nostris \\
\hline Justus est Dominus & [sección omitida] & [sección omitida] \\
\hline \multicolumn{1}{|c|}{ in circuitu eius hostes } & in circuitu eius hostes & peccaverunt, et non sunt \\
\hline Virgines mee et iuvenes & menstruis inter eos & et nos iniquitates eorum \\
\hline Hierusalem convertere & Hierusalem convertere & Hierusalem convertere \\
\hline Dominum Deum tuum & Dominum Deum tuum & Dominum Deum tuum \\
\hline
\end{tabular}

La publicación de obras de compositores post mortem no fue una práctica editorial nueva, pues a través de ella impresores y libreros aseguraban mayores ingresos al evitar una vinculación contractual con los autores. La preparación de una colección de nueve lamentaciones —atribuida en su totalidad a Morales- revela que estos impresos fueron preparados con fines lucrativos para rentabilizar el nombre y prestigio del compositor español en el mercado internacional. Además, la muerte de Festa (†1545) y Morales (†1553) favoreció la alteración de los textos y la música original de algunas de estas lecciones para adecuar esta «farsa editorial» a la práctica romana pretridentina. En la actualidad, se conservan cuatro ejemplares de las lamentaciones impresas de Morales en las ciudades de Bolonia, Lucca, Viena y Uppsala, pero la difusión de estos libros no se limitó de forma exclusiva a Italia u otros centros católicos del centro o del norte de Europa. La localización de versiones de estas obras en varios manuscritos españoles y portugueses sugiere una más que probable circulación de este repertorio en la Península Ibérica ${ }^{23}$. Un

${ }^{23}$ Los manuscritos españoles que guardan una estrecha vinculación con las ediciones impresas son E-TZ 1 y E-CU 34 (sólo se conservan las voces del altus-quintus-bassus del verso «Cervicibus 
descubrimiento que pone en tela de juicio la percepción histórica que Rubio proyectó sobre los impresos de 1564. Estas ediciones no deberían valorarse simplemente como una falacia editorial por el hecho de que sólo cuatro lamentaciones sean del compositor español o incluso por la manifiesta alteración de su contenido original. Por el contrario, se debe destacar su importancia histórica por su amplia comercialización y las implicaciones derivadas de la atribución de algunas lamentaciones de Festa a Morales, prueba de la popularidad que disfrutó el maestro hispalense en la segunda mitad del siglo XVI.

\section{Adaptaciones postridentinas en Roma, Toledo, México y Guatemala}

Otros ejemplos de la adaptación postridentina de las lamentaciones de Morales en fuentes manuscritas han sido localizados en archivos musicales tan importantes como la capilla pontificia en Roma, la Catedral de Toledo y las catedrales hispanoamericanas de México, Puebla y Guatemala, entre algunas de las sedes más destacadas del siglo XVI. Algunas de sus lecciones de Tinieblas fueron modificadas por escribas, músicos o maestros de capilla de estas instituciones con la finalidad de adecuarlas al rezado romano tridentino. Sobre esta cuestión conviene señalar que el impacto del Breviarium romanum de Pío V (1568) en el catolicismo debe ser reconsiderado, al menos en lo que respecta al género lamentación. A pesar de que este libro postridentino estaba destinado a regir la práctica litúrgica de los textos del Oficio Divino, la normalización textual que se reconoce en este repertorio procede de los textos fijados en los Officium Hebdomadae Sanctae secundum curiam romanam postridentinos ${ }^{24}$. Todas las adaptaciones que se hicieron de las lamentaciones de Morales concuerdan con el rezado romano determinado en las ediciones de estos Oficios de Semana Santa.

nostris»). La Catedral de Cuenca conservó en sus archivos más copias de sus lamentaciones; véase Fuente, Jose Luis de la. «Inventorium Librarium Musicae. Nueva aportación documental sobre el archivo musical de la Catedral de Cuenca (siglos XVII- XVIII)». Anuario Musical, 62 (2007), pp. 187 y 201: «Un libro de lamentaciones encuadernado en becerro que contiene 3 lamentaciones / escritas en pergamino que son de Morales, dos $a 5$ y una $a$ 6». A esta lista de manuscritos debe añadirse un ejemplar perdido que fue donado a la Catedral de Badajoz por su canónigo don Pedro de Vergara. Véase Kastner, Santiago. «La música en la Catedral de Badajoz (años 15201603)». Anuario Musical, 12 (1957), p. 144: «[9-I-1602] Más cinco cuadernitos de lamentaciones del mismo Morales, de molde encuadernados en pergamino escrito».

${ }^{24}$ Véase Sol, Manuel del. «Rethinking Victoria's Lamentations in Post-Tridentine Rome». Estudios. Tomás Luis de Victoria. Studies. Javier Suárez-Pajares y Manuel del Sol (eds.). Madrid, Instituto Complutense de Ciencias Musicales, 2013, pp. 55-75. 
El manuscrito I-Rvat CG XII.3 de la Cappella Giulia no es la única fuente vaticana que conserva lamentaciones de Morales, ya que el códice I-Rvat CS 198 de la Cappella Sistina preserva otras cuatro lecciones atribuidas a este compositor (Tabla 5). La descripción latina de su portada confirma que Pedro Bastianello de Triviano, maestro de capilla en la Cappella Pontificia a comienzos de siglo XVIII, reunió en este manuscrito una colección de seis libros independientes (copiados por diferentes copistas desde el siglo XVI hasta el siglo XVIII) que contienen una antología polifónica de lamentaciones de diversos compositores: Morales (4), Festa (2), Palestrina (3) y anónimos (6); y el Introito, Gradual, Ofertorio y Comunión de una misa monódica del «Spiritu sancto a septuagesima usque ad pascha» en notación cuadrada ${ }^{25}$.

TABLA 5. Lamentaciones de Jeremías del segundo y quinto libro del manuscrito I-Rvat CS 198.

\begin{tabular}{|c|c|c|l|c|c|}
\hline Folios & \multicolumn{2}{|c|}{ Lecciones } & \multicolumn{1}{c|}{ Libro segundo } & Voces & Autor \\
\hline $10 \mathrm{v}-13 \mathrm{r}$ & Jueves Santo & I & Incipit Lamentatio. Quomodo sedet sola & 4 & Anónimo \\
\hline $14 \mathrm{v}-17 \mathrm{r}$ & Jueves Santo & II & Vau. Et egressus est & 4 & Anónimo \\
\hline $17 \mathrm{v}-21 \mathrm{r}$ & Jueves Santo & III & Iod. Manum suam misit & $5(3,4)$ & ¿Morales? \\
\hline \multicolumn{5}{|c|}{ Libro quinto } \\
\hline $52 \mathrm{v}-55 \mathrm{r}$ & Jueves Santo & II & Vau. Et egressus est & 4 & Morales \\
\hline $55 \mathrm{v}-60 \mathrm{r}$ & Jueves Santo & III & Iod. Manum suam misit & $5(3,4)$ & Morales \\
\hline $60 \mathrm{v}-64 \mathrm{r}$ & Viernes Santo & II & Lamed. Matribuis suis & $4(2,3)$ & Festa \\
\hline $64 \mathrm{v}-69 \mathrm{r}$ & Viernes Santo & III & Aleph. Ego vir videns & $6(3,4)$ & Morales \\
\hline $69 \mathrm{v}-73 \mathrm{r}$ & Sábado Santo & II & Aleph. Quomodo obscuratum est & $6(2,3,4)$ & Festa \\
\hline
\end{tabular}

En el segundo libro de I-Rvat CS 198, la lección Iod. Manum suam misit está atribuida a Morales; sin embargo, como se verá más adelante, esta autoría es discutible. Por el momento, solamente interesa saber que se trata de una obra que no concuerda con ninguna de sus lamentaciones del Vaticano. En cambio, las lamentaciones de Morales (3) y Festa (2) del quinto libro no ofrecen ninguna duda: no son una copia de sus originales pretridentinos, sino adaptaciones postridentinas (Tabla 6) ${ }^{26}$.

${ }^{25}$ Llorens, José María. Capellae Sixtinae Codices. Ciudad del Vaticano, Biblioteca Apostólica Vaticana, 1960, p. 214: «Sedente Benedicto XIII [...] R.D. Petro Bastianello de Triviano / Magistro Cappellae Pontificiae / Pro tempore existente / Restauravit Anno Domin / MDCCXXIV. Codex compluribus exaratus manibus, diversis libellis constat ut perspicue demonstrat praeter chartae varietatem, varius foliarum modules. In partes sex dividitur: [(1) ff. 1-9; (2) ff. 10-25; (3) ff. 26-45; (4) ff. 46-51; (5) ff. 52-73; y (6) ff. 74-89] et in unum volumen anno 1724 ut videtur compactus».

${ }^{26}$ La conexión de las ediciones impresas con el códice I-Rvat CS 198 es improbable porque la música del verso «Justus est Dominus» —excluido en las ediciones impresas— se utilizó en la adaptación postridentina de la lamentación Aleph. Ego vir videns. Véanse la Tabla 6 y Sol, M. «Rethinking Victoria's Lamentations...», p. 68. 
Tabla 6. Adaptaciones postridentinas de las lamentaciones originales de Cristóbal de Morales y Costanzo Festa en I-Rvat CS 198.

\begin{tabular}{|c|c|c|c|}
\hline Lamentaciones & Compositor & I-Rvat CS 198 & I-Rvat CG XII.3 \\
\hline Jueves Santo & Morales & fols. $52 \mathrm{v}-55 \mathrm{r}$ & fols. $126 \mathrm{v}-130 \mathrm{r}$ \\
\hline $\begin{array}{l}\text { Lección II } \\
\text { I:6,8,9 }\end{array}$ & & $\begin{array}{l}\text { Vau. Et egressus est } \\
\text { Heth. Peccatum peccavit } \\
\text { Vide, Domine, afflictionem } \\
\text { Hierusalem convertere }\end{array}$ & $\begin{array}{l}\text { Coph. Vocavi amicos meos } \\
\text { Ain. Audierunt quia ingemisco } \\
\text { [Sin concordancia localizada] } \\
\text { Hierusalem convertere }\end{array}$ \\
\hline Jueves Santo & Morales & fols. $55 v-60 r$ & fols. $130 \mathrm{v}-134 \mathrm{r}$ \\
\hline $\begin{array}{c}\text { Lección III } \\
\text { I:10,12,14 }\end{array}$ & & $\begin{array}{l}\text { Iod. Manum suam misit } \\
\text { De quibus preceperas } \\
\text { Lamed. O vos omnes } \\
\text { Num. Vigilavit ingum } \\
\text { iniquitatum } \\
\text { Infirmata est virtus } \\
\text { Hierusalem convertere }\end{array}$ & $\begin{array}{l}\begin{array}{l}\text { Ain. Idcirco ego plorans } \\
\text { quoniam invaluit }+ \text { longue factus est } \\
\text { convertens animan } \\
\text { me consolador } \\
\text { quia longue. }\end{array} \\
\text { Samech. [Sin concordancia localizada] } \\
\text { Num. Vigilavit iugum iniquitatum } \\
\text { Infirmata est virtus \& Dedit me } \\
\text { Dominus } \\
\text { Hierusalem convertere }\end{array}$ \\
\hline Viernes Santo & Festa & fols. $60 \mathrm{v}-64 \mathrm{r}$ & fols. $26 r-30 r$ \\
\hline $\begin{array}{l}\text { Lección II } \\
\text { II:12-13,15 }\end{array}$ & & $\begin{array}{l}\text { Lamed. Matribus suis } \\
\text { Mem. Cui comparabote } \\
\text { Samech. Plauserunt super te } \\
\text { Gaudium universae terrae? } \\
\text { Hierusalem convertere }\end{array}$ & $\begin{array}{l}\text { Phe. Audite obsecro } \\
\text { Syn. Gaude et laetare } \\
\text { Res. [Nueva] + a singulu meo et } \\
\qquad \begin{array}{l}\text { iudicasti, Domine } \\
\text { Redemptor vitae meae } \\
\text { Hierusalem convertere }\end{array}\end{array}$ \\
\hline Viernes Santo & Morales & fols. $64 v-69 r$ & fols. $134 \mathrm{v}-139 \mathrm{r}$ \\
\hline $\begin{array}{c}\text { Lección III } \\
\text { III:1-6 }\end{array}$ & & $\begin{array}{l}\text { Aleph. Ego vir videns } \\
\text { Et adduxit in tenebras } \\
\text { Beth. Vetustam fecit } \\
\text { In tenebrosis collocavit me } \\
\text { Hierusalem convertere }\end{array}$ & $\begin{array}{l}\text { Phe. Expandit Syon } \\
\text { in circuitu eius hostes + menstruis } \\
\text { Sade. Justus est Dominus } \\
\text { virgines mea } \\
\text { Hierusalem convertere }\end{array}$ \\
\hline Sábado Santo & Festa & fols. $69 v-73 r$ & fols. 43v-50r \\
\hline $\begin{array}{l}\text { Lección II } \\
\text { IV:1-2, 4-5 }\end{array}$ & & $\begin{array}{l}\text { Aleph. Quomodo obscu- } \\
\text { ratum } \\
\text { Beth. Filii Sion } \\
\text { Gimel. Sed et lamie } \\
\text { Daleth. Adhaesit lingua } \\
\text { He. Qui vescebantur } \\
\text { Hierusalem convertere }\end{array}$ & $\begin{array}{l}\text { Lamed. Clamavit cor eorum } \\
\text { Gimel. [Sin concordancia localizada] } \\
\text { [Omitido] } \\
\text { Zain. Adhesit lingua } \\
\text { [Omitido]. Lubricaverum vestigia } \\
\text { Hierusalem convertere }\end{array}$ \\
\hline
\end{tabular}


Estas cinco lamentaciones fueron cuidadosamente copiadas por Johannes Parvus entre 1578 y $1579^{27}$. Estas fechas coinciden precisamente con la revisión litúrgica realizada durante el pontificado de Gregorio XIII con el propósito de evaluar qué obras conservadas en los archivos vaticanos eran aptas para su uso en la liturgia postridentina de la Capilla Papal. Esta tarea estuvo inicialmente dirigida por Giovanni Pierluigi de Palestrina y Annibale Zoilo, quienes casi con total certeza fueron los responsables de modificar varias de las lamentaciones pretridentinas de Morales y Festa que, previamente, habían sido copiadas en el manuscrito I-Rvat CG XII.3. En la actualidad, está demostrado con toda seguridad que Palestrina (y Francesco Soriano) escribió voces adicionales en varios de los Magnificat de Morales - hoy copiados en el manuscrito I-Rvat CG VIII.3928_; sin embargo, aún no se había considerado que Palestrina y Zoilo pudieran haberse implicado en la reestructuración de varias lamentaciones de Morales y Festa. En caso afirmativo, no sólo se confirma la veneración y admiración que Palestrina profesaba hacia la música de estos autores, sino también la pervivencia de sus obras en el repertorio vivo de la Capilla Papal. Sobre esta cuestión, se debe insistir en que las investigaciones de Giuseppe Baini, Günther Massenkeil y Robert Stevenson han planteado un marco cronológico de la práctica polifónica de las lamentaciones en la capilla pontificia que es cuestionable. En opinión de estos estudiosos, las lecciones de «Carpentras» «fueron regularmente cantadas en San Pedro hasta el año de 1587», es decir, hasta que fueron reemplazadas por las de Palestrina ${ }^{29}$. Sin embargo, a pesar de que esta presunción ha sido ampliamente difundida en la historiografía musical contemporánea, no hay duda de que junto a las lamentaciones de «Carpentras», las de Festa y Morales se cantaron durante la mayor parte del siglo $\mathrm{XVI}^{30}$. Las lecciones de I-Rvat CG XII.3 y las adaptaciones postridentinas de I-Rvat CS 198

${ }^{27}$ Véanse Brauner, M. The Parous Manuscripts..., pp. 256-274; y Brauner, M. «Traditions in the Repertory of the Papal Choir in the Fifteenth and Sixteenth Centuries». Papal Music and Musicians in Late Medieval and Renaissance Rome. Richard Sherr (ed.). Oxford, Oxford University Press, 1998, pp. 169-170.

${ }^{28}$ Llorens, J. M. Le opere musicali della Cappella Giulia..., pp. 69-74.

${ }^{29}$ MassenkeIl, Günther. «Lamentations». New Grove Dictionary of Music and Musicians. 29 vols. Stanley Sadie y John Tyrrell (eds.). Londres, Macmillan, 2001, vol. XIV, p. 189: «Lamentations by Carpentras were regularly sung in S. Pietro until 1587». Sobre esta discusión, véanse BAINI, Giuseppe. Memorie storico-critiche della vita e delle opere di Giovanni Pierluigi da Palestrina. Roma, Dalla Societa Tipografica, 1828, p. 190; HABERL, Franz Xaver. Biographischer und thematicscher Musikkatalog des päpstlichen Kapellarchives im Vatikan zu Rom. Leipzig, Breitkopf \& Härtel, 1888, p. 172; y Stevenson, R. La música en las catedrales españolas..., p. 115.

${ }^{30}$ Brauner, M. «Traditions in the Repertory of the Papal Choir...», p. 170. 
sugieren una interpretación ininterrumpida de estas obras desde 1544 hasta la década de 1580 .

La relevancia musicológica de los ejemplares revisados de Morales y Festa no se limita únicamente a las variantes musicales detectadas en estas composiciones. La colación crítica de los versos seleccionados y la reubicación litúrgica de que fueron objeto estas cinco lamentaciones pretridentinas ofrece una valiosa información para el estudio de la práctica postridentina en la capilla pontificia ${ }^{31}$. Por el momento, sólo se conocen las variantes que se hicieron en algunas de las lamentaciones de Morales y Festa en la Roma de finales del siglo XVI, aunque no se descarta similar destino para otras lecciones de Tinieblas escritas por otros polifonistas ${ }^{32}$. En relación al compositor español, no se ha localizado hasta ahora ninguna adaptación de la lección Zain. Candidiores nazarei y, por consiguiente, puede pensarse que la circulación de esta composición fuera muy escasa después de la implantación del rezado tridentino en Italia y España.

Las lamentaciones de Morales copiadas para la Capilla Papal no fueron las únicas obras modificadas para su pervivencia. Michael Noone y Graeme Skinner han demostrado que la lamentación Incipit Lamentatio Hieremiae Prophetae. Aleph. Quomodo sedet sola de un manuscrito de la Catedral de Toledo (E-Tc 21) fue adaptada al rezado romano postridentino. Esta composición incluía originalmente una sección polifónica que Morales compuso sobre los textos del exordium del libro de las lamentaciones, «Et factum est postquam», y no la versión reducida «Incipit Lamentatio Hieremiae Prophetae» que conserva en la actualidad ${ }^{33}$. Además, para su correcta adecuación se le añadieron dos versos más — «Daleth. Viae Sion» y «He. Facti sunt»-compuestos probablemente por Andrés de Torrentes o Ginés de Boluda ${ }^{34}$. Otras copias de esta misma obra —conservadas en E-MO 753 y E-BAE 4- tuvieron un destino similar a la adaptación realizada en la

${ }^{31}$ Sol, M. «Rethinking Victoria's Lamentations...», pp. 66-69. Victoria rindió homenaje a las lamentaciones de Morales (y también a Festa en la primera lección del Jueves Santo) al parafrasear el melisma de la letra hebrea Phe de la lección Expandit Syon, al inicio del verso «Convertere» de su tercera lamentación del Jueves Santo Iod. Manum suam misit. Ibid., pp. 66-67.

${ }^{32}$ Varias lamentaciones pretridentinas escritas por algunas de las más grandes figuras de la polifonía vocal religiosa del Renacimiento español también se adaptaron al marco litúrgico del rezado romano para garantizar su pervivencia tras Trento. Se han localizado ejemplos similares en algunas de las lamentaciones de Francisco Guerrero, Rodrigo de Ceballos, Hernando Franco y Santos de Aliseda. Véanse SNow, R. A New-World Collection of Polyphony..., pp. 54-62 y 100-102; y Sol, M. La tradición monódica hispana...

${ }^{33}$ Noone, M. y Skinner, G. «The Nuevo Rezado...», pp. 3-20.

${ }^{34}$ Ibid., pp. 9-20. 
Catedral de Toledo ${ }^{35}$. No obstante, las introducciones «Incipit Lamentatio Hieremiae Prophetae» de los manuscritos E-Tc 21, E-MO 753 y E-BAE 4 demuestran que son versiones distintas, por lo que es probable que los maestros de capilla de estas instituciones escribieran una nueva sección polifónica para este verso. En efecto, la uniformidad textual tridentina impuesta desde Roma produjo cambios significativos en la lamentación toledana de Morales, pero con el trabajo conjunto de Noone y Skinner se ha podido restaurar la música y el texto del exordium original de la lamentación Et factum est postquam. Aleph. Quomodo sedet sola a través de la concordancia que esta composición guarda estrechamente con el manuscrito MEX-Pc 2 de la Catedral de Puebla (México) y un arreglo para voz y vihuela que Miguel de Fuenllana publicó en su libro de música Orphénica lyra (Sevilla, 1554) ${ }^{36}$.

Sobre el uso de melodías preexistentes en este repertorio se debe comentar que la utilización de un tonus lamentationum como base compositiva permite identificar con cierta precisión la filiación de una lamentación polifónica con una tradición monódica específica. En las tres lecciones que Morales escribió en Roma para uso en la Capilla Papal no se detecta la cita estricta de un tonus lamentationum. De hecho, al contrario de lo que previamente hiciese Escribano en su etapa romana, Morales se alejó de la paráfrasis rigurosa de los tonos hispanos y romanos en la escritura polifónica de sus lamentaciones Coph. Vocavi amicos meos, Num. Vigilavit iugum iniquitatum y Phe. Expandit Syon ${ }^{37}$. En estas obras tan sólo se reconoce una mera cita motívica de las principales entonaciones de los tonos romanos e hispanos. De acuerdo con la praxis de la capilla pontificia hubiera sido más apropiado emplear como cantus firmus la conducta recitativa de un tono romano — como ha sido posible identificar en el verso «Melius fuit occisis gladio» de la lamentación Zain. Candidiores nazarei- pero, al examinar el contenido musical de las tres lecciones del I-Rvat CG XII.3,

${ }^{35}$ Para consultar el catálogo de las obras contenidas en E-BAE 4, véase MARÍN LóPEZ, Javier. «Un tesoro musical inexplorado: los libros de polifonía de la Catedral de Baeza». Estudios de Humanismo Español. Baeza en los siglos XVI y XVII. María Águeda Moreno (ed.). Baeza, Ayuntamiento de Baeza, 2007, pp. 319-346, en pp. 342-344.

${ }^{36}$ La identificación de dos lecciones de Tinieblas pretridentinas arregladas para voz y acompañamiento de vihuela documentan la presencia de este género en el ámbito profano, fuera del marco litúrgico para el que fueron concebidas. Véase Sol, Manuel del. «Lamentaciones para vihuela fuera de los muros de la catedral». Roseta, 3 (2009), pp. 6-17.

${ }^{37}$ Véanse Juan Escribano (+ 1557). Seis Lamentaciones. Dionisio Preciado (ed.). Madrid, Alpuerto, 2006; y Sol, Manuel del. «Tradición hispana en las lamentaciones polifónicas del Oficio de Tinieblas: apuntes sobre tonus lamentationum hispanos en el siglo XVI». Revista de Musicología, XXXIII, no 1-2 (2010), pp. 264-266. 
está claro que esa posibilidad fue desestimada por el propio compositor o que el empleo de un tono hispano como cantus firmus resultase una decisión poco apropiada en la práctica musical de la Capilla Papal en aquel periodo ${ }^{38}$.

Después de la libertad con la que Morales abordó la composición de sus lamentaciones vaticanas - ya que el caso de la lección Zain. Candidiores nazarei continúa siendo una incógnita - contrasta el hecho de que tan sólo cuatro años más tarde Morales escribiera a su regreso a España una lamentación polifónica basada estrictamente en el canto llano del tradicional tono toledano ${ }^{39}$. Una lamentación que, por otra parte, permaneció en uso dentro del repertorio de la capilla de música de la Catedral de Toledo y otras instituciones eclesiásticas - como las capillas catedralicias de Baeza (E-BAE 4) y Puebla (MEX-Pc 2), y varios monasterios de la Orden de San Jerónimo (E-MO 753, E-E 4 y E-VAar 3016) — desde mediados del siglo XVI hasta al menos la primera mitad del siglo XVII ${ }^{40}$.

Esta lamentación que Morales compuso en la catedral toledana (E-Tc 21) no fue la única lección que el maestro hispalense escribiese a su regreso a España. Después de renunciar al magisterio toledano en 1547 realizó la que fue, muy probablemente, una serie pretridentina - hoy incompleta- de tres lamentaciones escritas para la capilla del duque de Arcos en Sevilla (1549-1551), la Catedral de Málaga (1551-1553) o una capilla musical establecida en la diócesis de Granada. Es esta una hipótesis aún no resuelta que asienta sus bases en los trabajos de Robert Snow y Martin $\mathrm{Ham}^{41}$. De este ciclo pretridentino de tres lamentaciones que Morales debió

${ }^{38}$ Sol, Manuel del. La tradición monódica hispana...

${ }^{39}$ Esta melodía de la tradición monódica de la iglesia de Toledo se reconoce fácilmente en la voz del altus, copiada igualmente en notación mensural en la transcripción que Miguel de Fuenllana hizo del original de Morales en su Orphénica Lyra (Sevilla, 1554, fols. 77r-81r). De hecho, los textos y el canto llano impreso en la edición del Passionarium toletatum de 1516 coincide rigurosamente con la melodía del altus de E-Tc 21 y del libro de vihuela de Fuenllana (RISM 1554 ${ }^{32}$ ).

${ }^{40}$ Memorial del estilo que se ha de guardar en esta santa iglesia de Toledo en todas las fiestas del año que se celebran con solemnidad de canto de órgano, señálense los puntos en que le ha de haber y el modo que se ha de guardar. Toledo, 1604. La Biblioteca Nacional de Madrid conserva una copia de este Memorial con la referencia E-Mn Ms. 14045 ${ }^{123}$. Este documento es una segunda copia — posiblemente de la mano de Francisco Asenjo Barbieri- realizada de E-Mn Ms. 14.045 ${ }^{122}$. El original de la Catedral de Toledo (copiado por José María Ibarbi) tiene la signatura 0.2.6.14. Sobre el ceremonial del Jueves Santo se detalló que «la primera lamentación es a canto de órgano [y] es la de Morales». Ibid., fol. 12v. Véase también ReynAud, François. La polyphonie tolédane son milieu des premiers témoignages aux environs de 1600. París, CNRS Editions, 1996, pp. 318-319.

${ }^{41}$ SNow, R. A New-World Collection of Polyphony..., pp. 61-62; y HAM, M. «Morales: The Canon...», p. 276: «These similarities may or may not suggest that the two lessons [E-PAbm 6829, E-Bim 1 and GCA-Gc 4] were part of a more extensive work that has been partly lost». 
componer después de su periodo en Toledo hoy solamente se conservan copias dispersas de dos de ellas: 1) Incipit Lamentatio. Aleph. Quomodo sedet sola -E-PAbm 6829 y E-Bim 1-; y 2) De Lamentatione Hieremiae Prophetae. Heth. Cogitavit Dominus - GCA-Gc 4-.

Sobre estas obras hay que destacar el hecho de que Morales acudió al fondo cantollanístico hispano de las lamentaciones para desarrollar su polifonía. Un reconocimiento ya puesto en valor, pero que continúa generando cierta discusión con respecto al origen de los tonos hispanos identificados en estas piezas. En un primer momento, las conclusiones de Snow vincularon el canto llano utilizado en estas lamentaciones a la tradición toledana ${ }^{42}$; pero esta presunción despertó cierta desconfianza en las más recientes investigaciones de $\mathrm{Ham}^{43}$. Afortunadamente, esta incertidumbre puede resolverse gracias a la concordancia que estas piezas de Morales tienen con la edición del Officium Hebdomadae Sanctae de 1560, esto es, la fuente pretridentina sevillana más próxima al entorno litúrgico y musical que vivió este compositor durante su etapa andaluza. Si se atiende a los textos fijados de la edición impresa de 1560, la lección Aleph. Quomodo sedet sola no plantea ningún problema litúrgico ya que, en efecto, la presencia de los tres primeros versos del capítulo primero de Jeremías (I:1-3) fue una praxis habitual pretridentina tanto en la tradición sevillana como en otras instituciones españolas contemporáneas. Este es, por tanto, un aspecto que no aporta ningún dato relevante a la discusión planteada. Sin embargo, el descubrimiento de una variante melódica significativa en el tono hispano utilizado por Morales en la lección Aleph. Quomodo sedet sola aporta algo de luz sobre la procedencia de este canto llano. Esta variante melódica también se encuentra en las lamentaciones de Francisco Guerrero y Hernando Franco ${ }^{44}$. Dicha identificación no resuelve

${ }^{42}$ Ibid., pp. 61-62.

${ }^{43}$ HAM, M. «Morales: The Canon...», p. 276, nota 29: «It may be observed that there is an apparent detail of the chant in the setting from GCA-Gc 4 which does not appear in the E-PAbm 6829 version (or in the five-voice Toledan setting), for example at b. 39 of Snow's edition. This particular turn of phrase does not appear either in any chant versions in Jane Hardie, The Lamentations of Jeremiah: Ten Sixteenth-Century Spanish Prints. Ottawa, 2003). It is unclear whether it is a distinct chant variant or a detail introduced by the composer, although I incline to former possibility».

${ }^{44}$ La tradición monódica toledana mantuvo su primera cuerda de recitación estable (en re) en la palabra «vidua» (del verso «facta est quasi vidua domina»), mientras que la tradición hispalense — según el libro de 1560 - fijó una variante que enfatizaba el acento de la palabra «vi»-du-a (mi-re-re) a través de un movimiento descendente de grados conjuntos. Morales tuvo en cuenta este motivo al citar el canto llano sobre el que desarrolló la polifonía de esta obra. Una conducta recitativa que también se reconoce en la palabra «civitas» (mi-re-re) del verso anterior o en otros pasajes como «non est qui consoletur», siempre en la voz del altus. El aspecto más 
desafortunadamente la incógnita de cuándo ni dónde Morales compuso esta obra, pero parece que existe una prueba musical coherente que acerca su composición al ámbito diocesano andaluz y lo aleja de una posible vinculación con la tradición monódica toledana. Al igual que sucedió con la copia manuscrita conservada en Toledo, la lección del Jueves Santo Aleph. Quomodo sedet sola -E-PAbm 6829 y E-Bim 1- no debió incluir en su origen la introducción reducida «Incipit Lamentatio» (que trasmite sólo el fragmento incompleto de la voz del tenor del E-Bim 1), sino una versión polifónica hoy perdida del prólogo «Et factum est postquam $»^{45}$.

También el tonus lamentationum citado por Morales en la lamentación Heth. Cogitavit Dominus de GCA-Gc 4 confirma la conexión que esta obra tiene con la tradición monódica y polifónica española, y de manera específica con la práctica regional andaluza. Como ya demostrase Snow, los textos de esta lectura se recitaban antes de Trento en las diócesis de Granada, Sevilla y, muy probablemente, también en Málaga ${ }^{46}$, coincidencia ceremonial que favoreció la pervivencia postridentina de esta obra en la Catedral de Guatemala, al haberse normalizado estos mismos versos pretridentinos con los de la primera lección del Viernes Santo. Además, el estudio y transcripción que Snow hizo de varias lamentaciones españolas conservadas en GCA-Gc 4 demuestra que el exordio «De Lamentatione Hieremiae Prophetae» de su lamentación Heth. Cogitavit Dominus no fue compuesto por el compositor hispalense sino que se trata, como en los casos anteriormente comentados, de una sección polifónica de nueva composición añadida poco después de la asimilación en la Catedral de Guatemala de la reforma textual tridentina ${ }^{47}$.

Las lamentaciones de Morales conservadas en las catedrales de México, Puebla y Guatemala ya cuentan con estudios detallados ${ }^{48}$. Las in-

importante de esta singularidad recitativa se relaciona con el hecho de que no sólo se dio en esta composición, sino que aparece igualmente adaptada en las lamentaciones Aleph. Quomodo sedet sola $(4 \mathrm{vv})$ de Guerrero y Franco, que incluso trasmiten de un modo más estricto el tonus lamentationum impreso en la edición sevillana de 1560. Los detalles analíticos en los que se basa este estudio están ampliamente desarrollados en Sol, M. La tradición monódica hispana...

${ }^{45}$ Véase más arriba la nota 42.

${ }^{46}$ Véase más arriba la nota 41.

${ }^{47}$ SNow, R. A New-World Collection of Polyphony ..., p. 61.

${ }^{48}$ Stevenson, R. La música en las catedrales españolas..., pp. 110-115; Snow, R. A New-World Collection of Polyphony..., pp. 61-62; y HAM, M. «Morales: The Canon...», pp. 272-277. Véase también MoRALES, Omar. «Actualización y reelaboración paródica de una lamentación de Cristóbal de Morales realizada por Pedro Bermúdez en el Nuevo Mundo». Congreso Internacional «Sones de ida y vuelta: músicas coloniales a debate (1492-1898)». Baeza, 3-5 de diciembre de 2013 (pendiente de publicación). Esta investigación permite conocer que Pedro Bermúdez reelaboró el contenido del exordio original «Et factum est postquam» de Morales para componer la versión Incipit 
vestigaciones realizadas por Stevenson, Snow y Ham sobre estas fuentes hispanoamericanas corroboran un contexto semejante al que tuvieron estas mismas obras en Italia y en la Península Ibérica. Por ejemplo, la dudosa composición de Palestrina sobre la lección Incipit Lamentatio Hieremiae Prophetae. Aleph. Quomodo sedet sola —copiada en MEX-Pc 1 y en GCA-Gc 4- permaneció indeterminada hasta que las investigaciones de Ham resolvieron definitivamente su autoría a favor del maestro español. En realidad, se trata de una reelaboración postridentina basada en la lamentación Num. Vigilavit iugum iniquitatum de I-Rvat CG XII. $3^{49}$. Una atribución incorrecta que desplaza el objeto de estudio de las lamentaciones de Morales hacia otros aspectos igualmente importantes como la autenticidad y autoría de sus composiciones, es decir, las dudosas o falsas atribuciones.

\section{Problemas de autenticidad y autoría}

En palabras de Stevenson «ningún compositor español del siglo XVI fue tan alabado en vida y durante doscientos años después de su muerte como lo fue Morales ${ }^{50}$. La enorme fama y reputación que disfrutó Morales en Europa e Hispanoamérica en los siglos XVI y XVII favoreció la atribución de obras que originalmente fueron escritas por otros autores. Sus lamentaciones no fueron ajenas a esta idiosincrasia propia de los grandes maestros de la Edad Moderna, por lo que no es de extrañar que la celebridad de su nombre fuera utilizada de manera interesada, como ya se ha comentado.

La compilación de los seis fascículos agrupados en el códice I-Rvat CS 198 conserva una cuarta lamentación que quedaba pendiente de examinar. Según la catalogación de Llorens, la tercera lección del segundo libro de esta colección aparece atribuida a «Moralis ${ }^{51}$; sin embargo, su

\footnotetext{
Lamentation Hieremiae Prophetae que conserva en MEX-Pc 2.

${ }^{49} \mathrm{Ibid}$., pp. 272-277. Otras variantes de esta lamentación se han localizado en fuentes manuscritas españolas (E-E 4 y E-VAar 3016).

${ }^{50}$ Stevenson, R. La música en las catedrales españolas..., p. 119.

${ }^{51}$ En relación a la investigación que Ham realizó sobre esta lamentación se concluye que esta pieza pudo haber sido compuesta por Morales, aunque también señala que sus voces y claves muestran un estilo de composición atípico si se compara con el resto de su producción. Véase HAм, M. «Morales: The Canon...», p. 277, nota 31: «It has not been possible to examine this setting in detail, as the manuscript is in poor condition and the available copy is very largely illegible».
} 
autoría no parece tan evidente (véase Tabla 5) ${ }^{52}$. En un primer momento se consideró a Palestrina el compositor de la lección Iod. Manum suam misit, pero su nombre fue tachado y reemplazado por el del maestro español. Además, la corrosión de la tinta ha hecho que esta lamentación, junto con las dos lecciones que la preceden, se conserve de un modo ilegible, lo que ha dificultado la realización de un análisis más exhaustivo. No obstante, el estudio y recuperación de esta serie de tres lamentaciones está a nuestro alcance al haberse localizado una copia concordante dentro de una antología de lamentaciones conservadas en un manuscrito de la Biblioteca del Convento de San Francisco en Bolonia (I-Bsf M.V.XX.1) ${ }^{53}$. En esta fuente se atribuyen cinco lamentaciones a Morales que concuerdan, en su totalidad, con otras cinco lecciones de I-Rvat CS 198 (Tabla 7).

Tabla 7. Atribuciones a Morales en I-BSf M.V.XX.1 y sus concordancias con I-Rvat CS 198.

\begin{tabular}{|c|c|}
\hline I-Bsf M.V.XX.1 & I-Rvat CS 198 \\
\hline $\begin{array}{c}\text { Cristóbal de Morales: Jueves Santo - Lectio I, } \\
\text { fols. 1v-2r }\end{array}$ & Anónimo: Jueves Santo - Lectio I, fols. 10v-13 \\
\hline $\begin{array}{c}\text { Incipit Lamentatio. Aleph. Quomodo sedet sola } \\
\text { civitas }\end{array}$ & $\begin{array}{c}\text { Incipit Lamentatio. Aleph. Quomodo sedet sola } \\
\text { civitas }\end{array}$ \\
\hline $\begin{array}{c}\text { Cristóbal de Morales: Jueves Santo - Lectio II, } \\
\text { fols. 2v-3r }\end{array}$ & $\begin{array}{c}\text { Anónimo: Jueves Santo - Lectio II, fols. 14v- } \\
17 \mathrm{r}\end{array}$ \\
\hline Vau. Et egressus est & Vau. Et egressus est \\
\hline $\begin{array}{c}\text { Cristóbal de Morales: Jueves Santo - Lectio III, } \\
\text { fols. 3v-5r }\end{array}$ & $\begin{array}{c}\text { Cristóbal de Morales?: Jueves Santo - Lectio } \\
\text { III, fols. 17v-21r }\end{array}$ \\
\hline $\begin{array}{c}\text { Iod. Manum suam misit } \\
\text { Cristóbal de Morales: Viernes Santo - Lectio I, } \\
\text { fols. 5v-7r }\end{array}$ & $\begin{array}{c}\text { Anónimo: Viernes Santo - Lectio I, fols. 46v- } \\
51 \mathrm{r}\end{array}$ \\
\hline De Lamentatione. Heth. Cogitavit Dominus & De Lamentatione. Heth. Cogitavit Dominus \\
\hline $\begin{array}{c}\text { Cristóbal de Morales: Viernes Santo - Lectio } \\
\text { III, fols. 10v-11r }\end{array}$ & $\begin{array}{c}\text { Cristóbal de Morales: Viernes Santo - Lectio } \\
\text { III, fols. 64v-69r }\end{array}$ \\
\hline Aleph. Ego vir videns & Aleph. Ego vir videns \\
\hline
\end{tabular}

\footnotetext{
${ }^{52}$ Llorens, J. M. Capellae Sixtinae Codices..., p. 214.

${ }^{53}$ Gino Zanotti catalogó este manuscrito formado por seis cuadernillos encuadernados en cartón. Véase Zanotri, Gino. Biblioteca del Convento di San Francesco di Bologna. 2 vols. Bolonia, Forni Editore Bologna, 1970, vol. 2, pp. 295-296. Si exceptuamos el salmo Miserere de Victoria, el resto de las obras preservadas en esta colección son lamentaciones de diversos autores: Palestrina (8), Victoria (9), Escribano (1), Morales (5) y Festa (9). En la hoja de guarda de la compilación del manuscrito aparece escrito el siguiente comentario: «Proprietas huius est Joan. Nicoletti Cappellae Pontificiae Cantoris. Lib.i num. VI». Este cantor vaticano del siglo XVIII y la copia de algunas lamentaciones procedentes de su archivo ponen en relación este manuscrito con el códice I-Rvat CS 198.
} 


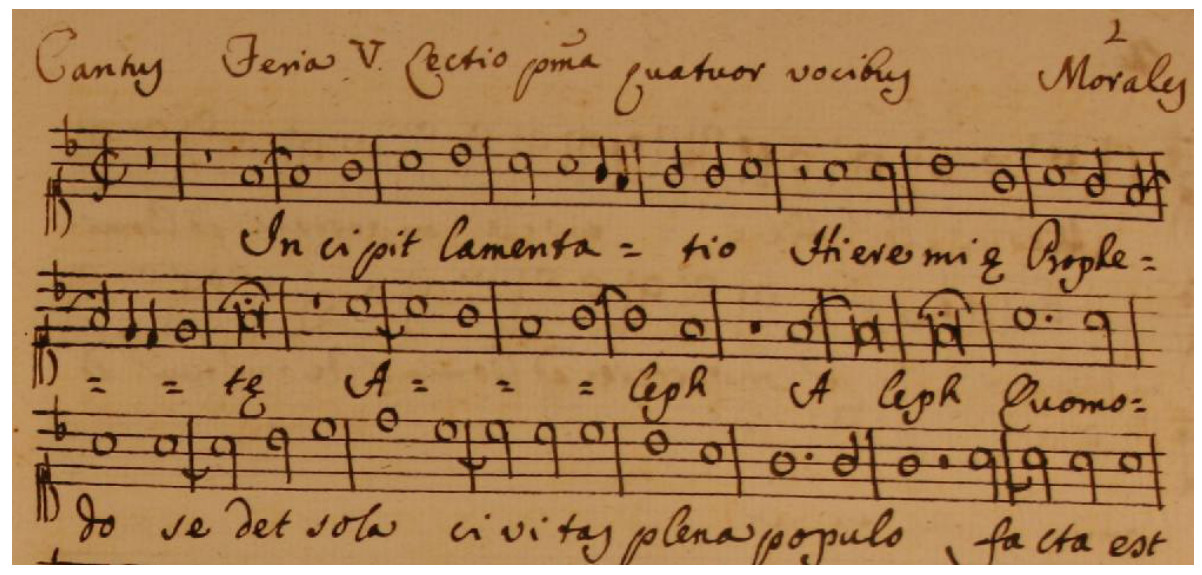

Ilustración 1. Inicio de Incipit Lamentatio. Aleph. Quomodo sedet sola (cantus), I-Bsf M.V.XX.1, fol. 2r.

La adscripción a Morales de la lección De Lamentatione Hieremiae Prophetae. Heth. Cogitavit Dominus en la fuente boloñesa debe considerarse errónea, ya que el fuerte carácter tonal de esta composición sugiere que esta obra fue compuesta por un autor desconocido en la segunda mitad del siglo XVII. En relación al resto de lamentaciones atribuidas a Morales, en I-Bsf M.V.XX.1 se descubre una transcripción de la adaptación postridentina Aleph. Ego vir videns y una copia de las tres lamentaciones del segundo cuaderno del I-Rvat CS 198: Incipit Lamentatio Hieremiae Prophetae. Aleph. Quomodo sedet sola, Vau. Et egressa est y Iod. Manum suam misit. Estas últimas composiciones deben analizarse como una entidad unitaria, ya que la lógica selección de sus textos (acorde con el rito romano postridentino) y un estilo musical homogéneo (en lo referente a su composición) sugiere que fueron obra de un mismo compositor. Según la catalogación que Llorens realizó de I-Rvat CS 198, la autoría de Morales de Iod. Manum suam misit podría hacerse extensible a las lecciones precedentes de este manuscrito. De hecho, las investigaciones de Johannes Ring respaldan esta presunción, al estar estas obras claramente atribuidas al compositor español en el manuscrito I-Bsf M.V.XX.1 (Ilustración 1) ${ }^{54}$.

A pesar de la claridad con que es posible reconocer el nombre de Morales en la voz del libro del cantus, las características musicales de estas lamentaciones se alejan notoriamente del estilo personal del compositor

\footnotetext{
${ }^{54}$ Quisiera agradecer a don Eugenio Petri el haberme facilitado una copia del manuscrito I-Bsf M.V.XX.1, así como el permiso de reproducción de la Ilustración 1. En relación a las investigaciones realizadas por Johannes Ring sobre las lamentaciones de Morales, véase RING, J. Studien zu den mehrstimmigen Lamentationen des 16. Jahrhundert..., pp. 182-202.
} 
español ${ }^{55}$. Además, un estudio exhaustivo de estas obras sugiere que el texto empleado en estas composiciones preserva lo que muy probablemente fueron sus versos originales ${ }^{56}$. Por todas estas razones, parece muy poco probable que las tres lamentaciones del segundo libro del I-Rvat CS 198 fueran compuestas por Morales, así que debieran considerarse como obras anónimas o de dudosa autoría. Otro ejemplo de la incorrecta atribución de obras a favor de Morales se ha descubierto en la lamentación Incipit Oratio Hieremie Prophete. Recordare, Domine, quid acciderit de I-Bc Q23. El copista de este manuscrito atribuyó en primer lugar esta composición a «Moralis hyspany», pero su nombre fue tachado después para escribir el de su auténtico autor, Philippe de «Verdeloth» ${ }^{57}$. Esta atribución está totalmente confirmada por la concordancia que esta pieza guarda con una copia anterior conservada en I-Rv 35-40.

\section{Conclusiones}

En relación al impacto que produjo el Concilio de Trento en el género lamentación se descubre que la paulatina asimilación de los libros litúrgicos postridentinos impuestos desde Roma precipitó un proceso de cambio muy significativo en este repertorio entre el último cuarto del siglo XVI

${ }^{55}$ El constante tratamiento homorrítmico de sus melodías y la inexistente actividad contrapuntística que presentan estas tres lamentaciones son rasgos estilísticos impropios en la obra de Morales. Además de estas características, la utilización del bassus como un mero sostén armónico trabajado por saltos y la escasa inspiración melódica en los melismas de las letras acrósticas hebreas indican una escritura musical que se aleja del estilo personal de este compositor en este género. Martin Ham ha insistido, además, en lo atípico de la combinación de sus voces y claves; véase HaM, M. «Morales: The Canon...», pp. 276-277.

${ }^{56}$ Este análisis se fundamenta en la hipótesis de que un mismo compositor parece haber trabajado de forma unitaria en estas tres lamentaciones a través de una recitación comprensible del texto, haciendo que su declamación polifónica sea sencilla e inteligible. Además, la estricta aplicación de las palabras de cada verso se potencia musicalmente de forma sistemática con un insistente tratamiento homorrítmico en todas las voces y con la ausencia de secciones intermedias contrapuntísticas. Estas observaciones sobre la aplicación del texto sugieren que se trata de lamentaciones postridentinas y así también lo acreditan sus versos, que coinciden exactamente con los propuestos con los libros litúrgicos romanos postridentinos de Semana Santa. A nivel musical, la entonación romana $(f a-s o l-l a)$ aparece en la voz del cantus, pero la recitación de su tenor (en $l a$ ) no se realiza de manera estricta. Se trata, por tanto, de una entonación libre diseñada por grados conjuntos (sib-la-la-sol-fa-sol-sol-la-la-la). En el resto de las voces de estas tres lamentaciones no se identifica una paráfrasis de diseños melódicos del tono hispano o romano.

${ }^{57}$ Véanse Lowinsky, Edward. «A Newly Discovered Sixteenth-Century Motet Manuscript at the Biblioteca Vallicelliana in Rome». Journal of the American Musicological Society, 3 (1950), pp. 173-232; y Haм, M. «Morales: The Canon...», p. 277. 
y la primera mitad del XVII. De hecho, la adecuación litúrgica de la reforma tridentina afectó de diversas maneras al catálogo polifónico de las lamentaciones de Jeremías: se compusieron nuevas obras acordes con los textos del rezado romano postridentino, los textos de algunas lecciones pretridentinas actualizaron su contenido al marco litúrgico reformado o simplemente - como parece que ocurrió en la mayoría de las ocasionesse retiraron de la práctica activa aquellas piezas cuyos versos quedaron obsoletos. La normalización textual del género después de Trento afectó particularmente a las lamentaciones españolas pretridentinas, desde Europa occidental hasta el Nuevo Mundo, siendo el contexto litúrgico de las lecciones de Morales especialmente interesante para el estudio de este fenómeno.

Existen suficientes fuentes manuscritas que confirman la difusión de sus lamentaciones sin ninguna o muy pocas modificaciones pero, en otras ocasiones, la música y textos originales se distorsionaron de tal manera en otros libros de polifonía que casi no se reconoce la versión auténtica de su autor. Sin embargo, a pesar de las variadas adaptaciones postridentinas identificadas en estas obras, las lamentaciones de Morales pueden ser finalmente comprendidas a través de la colación crítica de las numerosas copias manuscritas que se conservan diseminadas en Europa e Hispanoamérica (véase el Catálogo del Apéndice). Algunas de las dificultades detectadas por Anglés y Rubio durante el proceso de edición de la Opera omnia de Morales - especialmente en el caso de sus lamentaciones- continúan siendo un problema complejo al que se enfrenta la edición de las obras completas de este compositor, por lo que aún se necesita un trabajo más exhaustivo, como ya se ha hecho con las nuevas ediciones de Josquin o Palestrina $^{58}$. Hay que tener en cuenta que el descubrimiento de nuevas piezas y fuentes desconocidas con música de Morales, el problema de la autenticidad de sus obras, la evaluación y comparación de fuentes manuscritas e impresas, variantes e intertextualidad, y la ordenación y método editorial de transcripción y catálogo de sus composiciones justificarían - entre muchos otros aspectos- el proyecto de una nueva edición revisada y ampliada de sus obras completas en el siglo XXI ${ }^{59}$.

${ }^{58}$ Anglés, H. «Problemas que presenta la nueva edición de las obras de Morales...», pp. 21-32; New Josquin Edition. 30 vols. Willem Elder et alii. (eds.). Utrecht, Koninklijke Vereniging voor Nederlandse Muziekgeschiedenis, 1987-; Fallows, David. Josquin. Tours, Brepols, 2009; The National Edition of Works of Giovanni Pierluigi da Palestrina. 55 vols. Francesco Luisi et alii. (eds.). Udine, Pizzicato Edizioni Musicali, 2002-.

${ }^{59}$ En los últimos años se han encontrado nuevos datos acerca de la vida y obra temprana de Morales en la Catedral de Plasencia; véanse Diego PACHECo, Cristina. «Morales in Plasencia and 
El caso de estudio de las lamentaciones de Morales también se presenta como un ejemplo extraordinario porque permite comparar en un mismo repertorio y en un breve espacio de tiempo las diferentes aproximaciones de este maestro en función del contexto institucional: en las lecciones de Tinieblas para su uso en la capilla pontificia de Roma no se reconoce el uso riguroso de un cantus firmus, mientras que en las lamentaciones compuestas en España es posible identificar el uso estricto de tonos hispanos. Este aspecto descubre la autoridad que desempeñó el uso de la tradición monódica hispana en las lamentaciones polifónicas españolas del Renacimiento ${ }^{60}$. En el plano litúrgico, la ausencia de una normalización de este género antes del Concilio de Trento ha provocado que la ordenación ceremonial de las lamentaciones pretridentinas de Morales sea incierta dentro del primer nocturno de los Oficios de Maitines del Triduo Sacro. Excepto las lamentaciones que fueron compuestas para ser la primera lección del Jueves Santo (E-Tc 21 y E-PAbm 6829) y del Viernes Santo (GCA-Gc 4), el resto no determina una localización específica, y en aquellas fuentes manuscritas en donde se detalló su emplazamiento litúrgico parece que se tipificó la disposición fijada en las ediciones impresas de 1564. Aún no es posible conocer si Morales compuso música para los textos de la última lamentación del Oficio de Tinieblas, la Oración de Jeremías. En caso afirmativo, alguna copia de esta lección podría conservarse perdida u oculta tras un anónimo pero, en cualquier caso, parece muy improbable que Morales, al ser un compositor activo antes de Trento y, por tanto, ajeno a la normalización del género, tuviese en mente componer un ciclo completo.

La importancia de las lamentaciones de Morales se relaciona con el canon de su obra y el uso de estas composiciones antes y después de Trento. No hay duda de que la fama internacional de sus lecciones de Tinieblas se originó en Roma, precisamente desde la práctica musical de la capilla pontificia, donde fueron obras muy conocidas. Este éxito amplió aún más su ya sólida y acreditada reputación como compositor en

‘New' Works from his Early Compositional Period». Acta Musicologica, 82, 1 (2010), pp. 71-86; así como otro grupo de obras desconocidas de Morales aún sin catalogar y falsas atribuciones de sus lamentaciones y otros géneros. Diego PACHeco, Cristina. Un nouvel apport a L'Etude de la musique espagnole de la Renaissance: le manuscrit 5 de la cathédrale de Valladolid et son contexte. 2 vols. Tesis Doctoral. Université de Paris IV-Sorbonne, 2005; Cristóbal de Morales: Sources, Reception, Influences...; Urchueguía, Cristina. «Cristóbal de Morales: Aims and Challenges of a New Edition...»; Noone, Michael y SkInNER, Graeme. «Morales in Toledo Cathedral Manuscripts (1543-1604)...»; y Sol, Manuel del. «New Works by Cristóbal de Morales in SilosA 21». Medieval and Renaissance Internacional Music Conference. Barcelona, 5-8 de julio de 2011 (ponencias inéditas).

${ }^{60}$ SoL, M. La tradición monódica hispana... 
su tiempo y permite concluir que las lamentaciones de Morales fueron, junto con sus misas y magníficats, las obras más conocidas del maestro. El número de copias manuscritas, las adaptaciones postridentinas que se hicieron de sus originales, las ediciones impresas apócrifas de 1564 y un pequeño grupo de falsas atribuciones son un testimonio más que certifica la preeminente celebridad que disfrutó Morales en vida y después de su muerte. Supusieron, además, una contribución muy destacada al género lamentación a través de la circulación y recepción de estas obras en los principales centros católicos del Renacimiento, lo que implicó la pervivencia de sus lamentaciones en el repertorio vivo de algunas de las más importantes capillas de música en Italia, Portugal, España e Hispanoamérica hasta bien entrado el siglo XVII. 


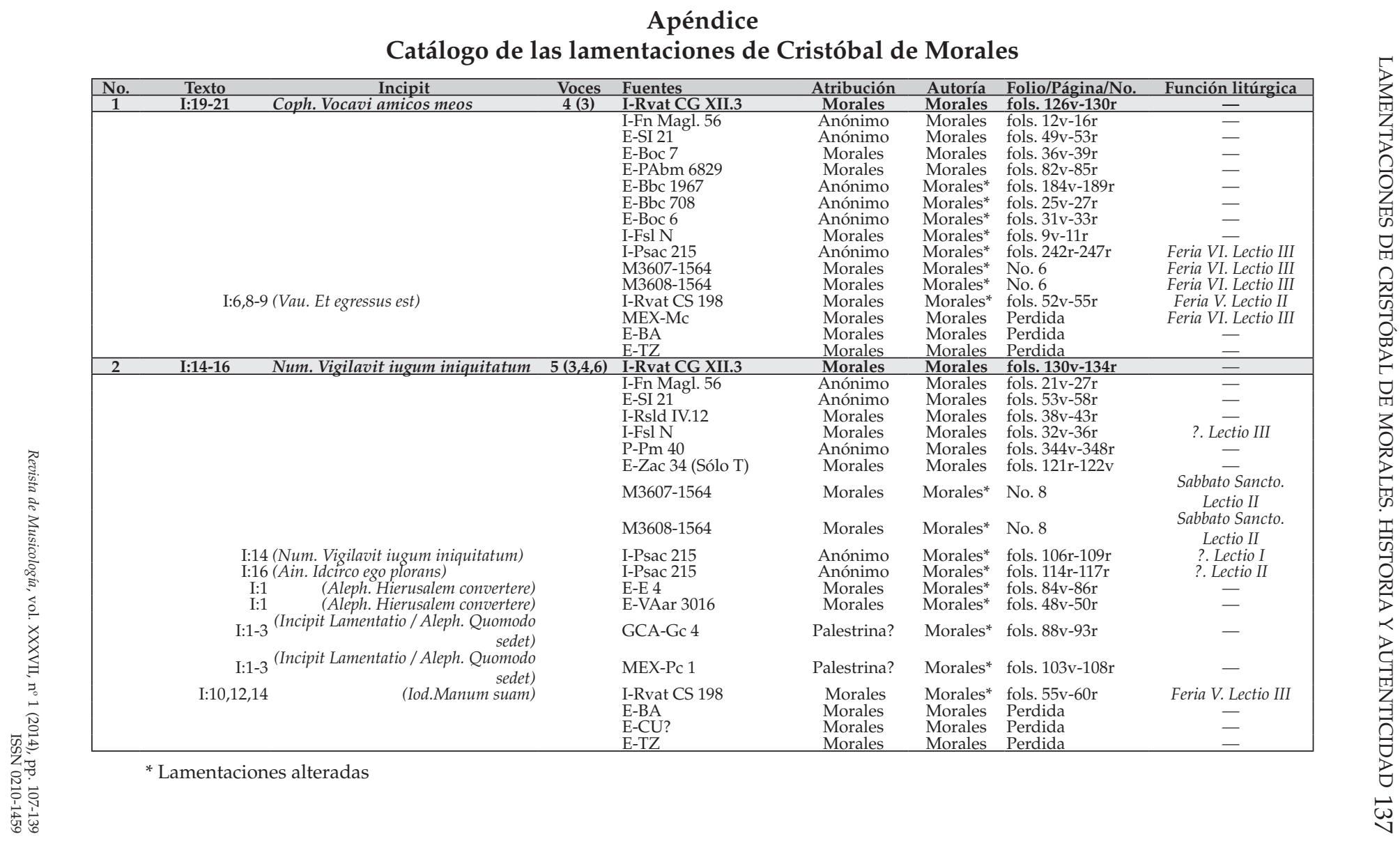




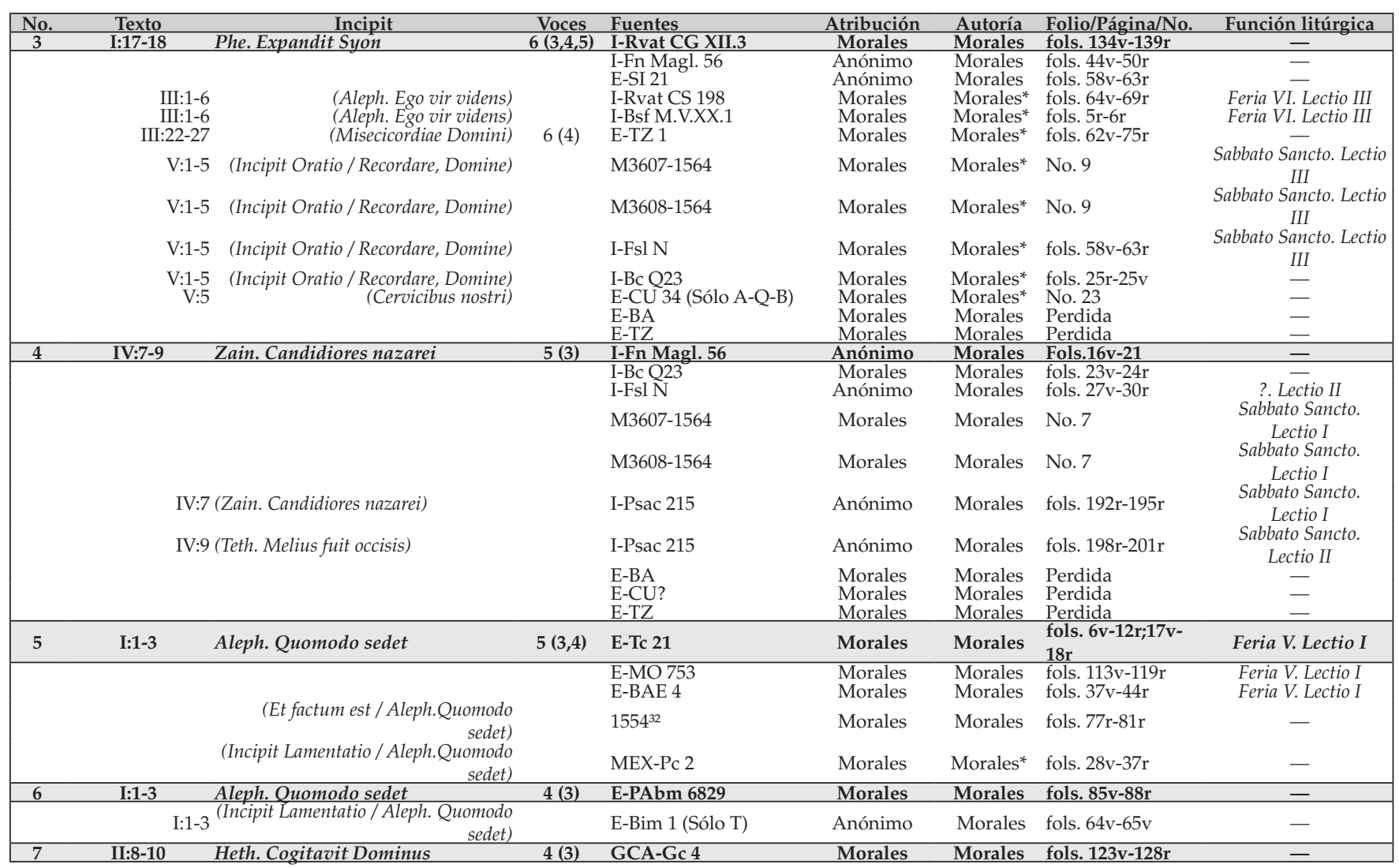




\section{Lamentaciones Dudosas / Falsas Autribuciones}

\begin{tabular}{|c|c|c|c|c|c|c|c|}
\hline$\frac{\text { No. }}{1}$ & $\begin{array}{lc}\text { Texto } & \text { Incipit } \\
& \text { - Incipit Lamentatio Hieremiae Propheae }\end{array}$ & $\frac{\text { Voces }}{5}$ & $\begin{array}{l}\text { Fuentes } \\
\text { E-Tc 21 } \\
\text { E-MO 753 } \\
\text { E-BAE 4 }\end{array}$ & $\begin{array}{l}\text { Atribución } \\
\text { Morales } \\
\text { Morales } \\
\text { Morales } \\
\end{array}$ & $\begin{array}{l}\text { Autoría } \\
\text { Anónimo } \\
\text { Anónimo } \\
\text { Anónimo }\end{array}$ & $\begin{array}{l}\text { Folio/Página/No. } \\
\text { fols. } 5 \mathrm{v}-6 \mathrm{r} \\
\text { fols. } 113 \mathrm{v}-114 \mathrm{r} \\
\text { fols. } 37 \mathrm{v}-38 \mathrm{r}\end{array}$ & $\begin{array}{c}\text { Función litúrgica } \\
\text { Feria V. Lectiol } \\
\text { Feria } V \text {. Lectio I } \\
\text { Feria V. Lectio I } \\
\end{array}$ \\
\hline 2 & - Incipit Lamentatio Hieremiae Propheae & 4 & E-Bim1 & Morales & Anónimo & fols. $64 \mathrm{v}-65 \mathrm{r}$ & \\
\hline 3 & I:1-2 Incipit Lamentatio / Aleph. Quomodo sedet & 4 & $\begin{array}{l}\text { I-Bsf M.V.XX.1 } \\
\text { I-Rvat CS } 198\end{array}$ & $\begin{array}{l}\text { Morales } \\
\text { Anónimo } \\
\end{array}$ & $\begin{array}{l}\text { Morales? } \\
\text { Morales? }\end{array}$ & $\begin{array}{l}\text { fols. 1r-2r (Soprano) } \\
\text { fols. 10v-13r }\end{array}$ & $\begin{array}{l}\text { Feria } V \text {. Lectio I } \\
\text { Feria V. Lectio I }\end{array}$ \\
\hline 4 & I:4-5 Daleth. Viae Sion lugent; He. Facti sunt & $5(3)$ & E-Tc 21 & Morales & Anónimo & fols. $12 \mathrm{v}-17 \mathrm{r}$ & Feria V. Lectio I \\
\hline 5 & I:6-7 Vau. Et egressus est & 4 & $\begin{array}{l}\text { I-Bsf M.V.XX.1 } \\
\text { I-Rvat CS } 198\end{array}$ & $\begin{array}{l}\text { Morales } \\
\text { Anónimo }\end{array}$ & $\begin{array}{l}\text { Morales? } \\
\text { Morales? }\end{array}$ & $\begin{array}{l}\text { fols. } 2 \mathrm{r}-3 \mathrm{r} \text { (Soprano) } \\
\text { fols. } 14 \mathrm{v}-17 \mathrm{r}\end{array}$ & $\begin{array}{l}\text { Feria V. Lectio II } \\
\text { Feria V. Lectio II }\end{array}$ \\
\hline 6 & I:10-12 Iod. Manum suam misit & $4(5)$ & $\begin{array}{l}\text { I-Bsf M.V.XX.1 } \\
\text { I-Rvat CS } 198\end{array}$ & $\begin{array}{l}\text { Morales } \\
\text { Morales? }\end{array}$ & $\begin{array}{l}\text { Morales? } \\
\text { Morales? }\end{array}$ & $\begin{array}{l}\text { fols. 3r-5r (Soprano) } \\
\text { fols. } 17 \mathrm{v}-21 \mathrm{r}\end{array}$ & $\begin{array}{l}\text { Feria V. Lectio III } \\
\text { Feria V. Lectio III } \\
\end{array}$ \\
\hline 7 & - De Lamentatione Hieremiae Prophetae & 4 & GCA-Gc 4 & Morales & Anónimo & fols. $122 \mathrm{v}-123 \mathrm{r}$ & - \\
\hline 8 & $\begin{array}{l}\text { De Lamentatione Hieremiae Prophetae / } \\
\text { Heth }\end{array}$ & 6 & E-TZ 1 & Morales & Anónimo & fols. $60 \mathrm{v}-62 \mathrm{r}$ & - \\
\hline 9 & $\begin{array}{l}\text { II:8-11 De Lamentactione / Heth. Cogitavit } \\
\text { Dominus }\end{array}$ & $5(4)$ & I-Bsf M.V.XX.1 & $\begin{array}{l}\text { Morales } \\
\text { Anónimo }\end{array}$ & Anónimo & fols. $5 r-7 r$ (Soprano) & Feria V. Lectio I \\
\hline 10 & I:1-2 Incipit Lamentatio / Aleph. Quomodo sedet & 4 & $\begin{array}{l}\text { I-Rvat CG XII.3 } \\
\text { I-Fn Magl. 56 } \\
\text { I-SanL IV-12 } \\
\text { I-Rsg 6/ Ms. } 8 \\
\text { M3607-1564 } \\
\text { M3608-1564 }\end{array}$ & $\begin{array}{l}\text { Festa } \\
\text { Anónimo } \\
\text { Anónimo } \\
\text { Morales } \\
\text { Morales } \\
\text { Morales } \\
\end{array}$ & $\begin{array}{l}\text { Festa } \\
\text { Festa } \\
\text { Festa } \\
\text { Festa } \\
\text { Festa } \\
\text { Festa } \\
\end{array}$ & $\begin{array}{l}\text { fols. } 18 \mathrm{v}-21 \mathrm{r} \\
\text { fols. } 93 \mathrm{v}-9 \mathrm{r} \\
\text { fols. } 27 \mathrm{v}-30 \mathrm{r} \\
\text { No. } 2 \\
\text { No. } 1 \\
\text { No. } 1 \\
\end{array}$ & $\begin{array}{c}\text { Feria V. Lectio I } \\
- \\
\text { Feria V. Lectio I } \\
\text { Feria V. Lectio I } \\
\text { Feria V. Lectio I }\end{array}$ \\
\hline 11 & II:13,12;IV:3;I:11-16 Lamech [Mem]. Cui comparabo te & $4(3)$ & $\begin{array}{l}\text { I-Rvat CG XII.3 } \\
\text { I-Bsf M.V.XX.1 } \\
\text { M3607-1564 } \\
\text { M3608-1564 }\end{array}$ & $\begin{array}{l}\text { Festa } \\
\text { Festa } \\
\text { Morales } \\
\text { Morales }\end{array}$ & $\begin{array}{l}\text { Festa } \\
\text { Festa } \\
\text { Festa* } \\
\text { Festa* }\end{array}$ & $\begin{array}{l}\text { fols. } 31 \mathrm{v}-34 \mathrm{r} \\
\text { fols. } 4 \mathrm{r}-5 \mathrm{r} \\
\text { No. } 2 \\
\text { No. } 2\end{array}$ & $\begin{array}{l}\text { Feria VI: Lectio II } \\
\text { Feria V. Lectio II } \\
\text { Feria V. Lectio II }\end{array}$ \\
\hline 12 & I:8-9,11 Heth. Peccatum peccavit & $4(2,3)$ & $\begin{array}{l}\text { I-Rvat CG XII.3 } \\
\text { M3607-1564 } \\
\text { M3608-1564 }\end{array}$ & $\begin{array}{l}\text { Festa } \\
\text { Morales } \\
\text { Morales }\end{array}$ & $\begin{array}{l}\text { Festa } \\
\text { Festa } \\
\text { Festa }\end{array}$ & $\begin{array}{l}\text { fols. } 21 \mathrm{v}-25 \mathrm{r} \\
\text { fol. } \\
\text { No. } 3 \\
\text { No. }\end{array}$ & $\begin{array}{l}\text { Feria V. Lectio II } \\
\text { Feria V. Lectio III } \\
\text { Feria V. Lectio III }\end{array}$ \\
\hline 13 & I:18;IV:21;III:56-62 Phe [Sade]. Audite obsecro universi & $4(2,3)$ & $\begin{array}{l}\text { I-Rvat CG XII.3 } \\
\text { I-Bsf M.V.XX.1 } \\
\text { I-Fn Magl. } 56 \\
\text { I-Psac 215 } \\
\text { I-Rvat CS } 198 \\
\text { M3607-1564 } \\
\text { M3608-1564 }\end{array}$ & $\begin{array}{l}\text { Festa } \\
\text { Festa } \\
\text { Anónimo } \\
\text { Anónimo } \\
\text { Festa } \\
\text { Morales } \\
\text { Morales }\end{array}$ & $\begin{array}{l}\text { Festa } \\
\text { Festa } \\
\text { Festa } \\
\text { Festa } \\
\text { Festa* } \\
\text { Festa } \\
\text { Festa }\end{array}$ & $\begin{array}{l}\text { fols. } 25 \mathrm{v}-30 \mathrm{r} \\
\text { fols. } 4 \mathrm{r}-5 \mathrm{r} \\
\text { fols. } 63 \mathrm{v}-68 \mathrm{r} \\
\text { fols. } 120 \mathrm{r}-123 \mathrm{r} \\
\text { fols. } 60 \mathrm{v}-64 \mathrm{r} \\
\text { No. } 4 \\
\text { No. } 4\end{array}$ & $\begin{array}{l}\text { Feria VI. Lectio II } \\
\text { Feria VI. Lectio III } \\
\text { Feria VI. Lectio II } \\
\text { Feria VI. Lectio I } \\
\text { Feria VI. Lectio I }\end{array}$ \\
\hline 14 & $\begin{aligned} & \text { IV:1-2;III:19-21 Zade. Quomodo obscuratum } \text { Zade. Quomodo obscuratum) } \\
& \text { (Sade. Quomodo obscuratum) } \\
& \text { (Sade. Quomode } \\
& \text { (Sade. Ouomodo obscuratum) }\end{aligned}$ & $4(3)$ & $\begin{array}{l}\text { I-Rvat CG XII.3 } \\
\text { I-Fn Magl. 56 } \\
\text { M3607-1564 } \\
\text { M3608-1564 }\end{array}$ & $\begin{array}{l}\text { Festa } \\
\text { Anónimo } \\
\text { Morales } \\
\text { Morales }\end{array}$ & $\begin{array}{l}\text { Festa } \\
\text { Festa } \\
\text { Festa* } \\
\text { Festa* }\end{array}$ & $\begin{array}{l}\text { fols. } 34 \mathrm{v}-38 \mathrm{r} \\
\text { fols. } 58 \mathrm{v}-63 \mathrm{r} \\
\text { No. } 5 \\
\text { No. } 5\end{array}$ & $\begin{array}{l}\overline{-} \\
\text { Feria VI. Lectio II } \\
\text { Feria VI. Lectio II }\end{array}$ \\
\hline 15 & $\begin{array}{c}\text { II:18;IV:4;V:18 Lamed [Sade]. Clamavit cor eorum } \\
\text { IV:1-2,4-5 } \\
\text { (Aleph. Quomodo obscuratum) }\end{array}$ & $\begin{array}{c}6(3,4) \\
6(2,3,4)\end{array}$ & $\begin{array}{l}\text { I-Rvat CG XII.3 } \\
\text { I-Rvat CS } 198\end{array}$ & $\begin{array}{l}\text { Festa } \\
\text { Festa }\end{array}$ & $\begin{array}{l}\text { Festa } \\
\text { Festa* }\end{array}$ & $\begin{array}{l}\text { fols. } 42 \mathrm{v}-50 \mathrm{r} \\
\text { fols. } 69 \mathrm{v}-73 \mathrm{r}\end{array}$ & Sabbato Sancto. Lectio II \\
\hline 16 & V:1-4,7-8 Incipit Oratio / Recordare, Domine & 5 & $\begin{array}{l}\text { I-Bc Q23 } \\
\text { I-Rv 35-40 } \\
\text { I-Fn Magl. } 56\end{array}$ & $\begin{array}{l}\text { Verdelot } \\
\text { Verdelot } \\
\text { Anónimo }\end{array}$ & $\begin{array}{l}\text { Verdelot } \\
\text { Verdelot } \\
\text { Verdelot }\end{array}$ & $\begin{array}{l}\text { fols. } 23 \mathrm{v}-25 \mathrm{r} \\
\text { No. } 26 \\
\text { fols. } 181 \mathrm{v}-186 \mathrm{r}\end{array}$ & $\begin{array}{l}= \\
=\end{array}$ \\
\hline
\end{tabular}





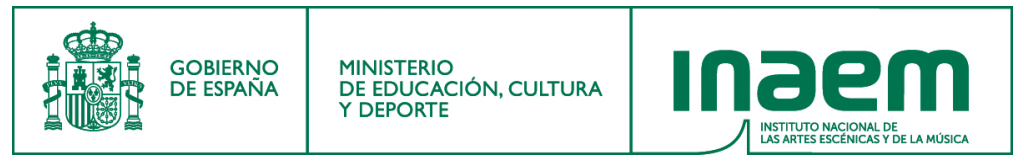

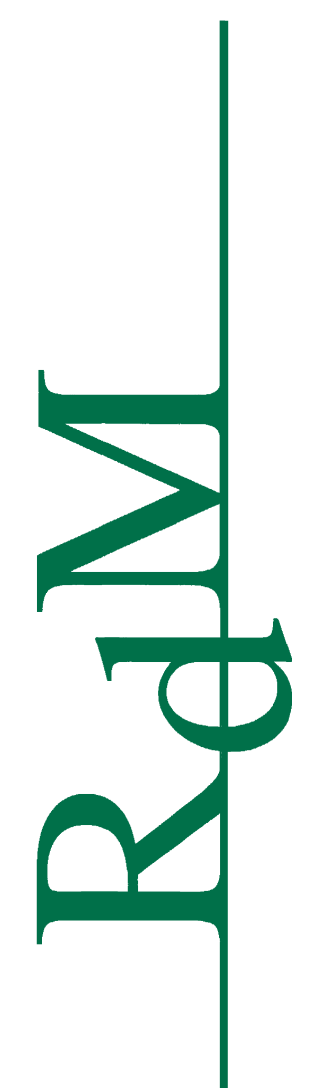

